\title{
REACTIONS OF SIMPLE UNSATURATED MOLECULES WITH THE POLYNUCLEAR CARBONYLS OF SOME GROUP VIII ELEMENTS
}

\author{
J. LEWIS and B. F. G. JoHNSON \\ Chemical Laboratory, University of Cambridge, UK
}

\begin{abstract}
The reactivity of polynuclear metal complexes involving metal-metal bonds with simple inorganic and organic molecules is considered. The basic structural forms of polynuclear aggregates is reviewed and the fluxional nature of polynuclear carbonyls is surveyed. The use of ${ }^{13} \mathrm{C}$ n.m.r. spectroscopy in determining the mechanism of fluxional interchange within the polynuclear carbonyls of Group VIII elements is described and the variety of pathways for exchange of carbonyl groups on a given metal centre or between different metal centres is established and correlated with the structure of the polynuclear species.

As the majority of structures of polynuclear carbonyls are based on triangular faced polyhedra, the dodecacarbonyls of iron, ruthenium and osmium have been used as the simplest model for considering the interaction of inorganic and organic molecules with a polynuclear aggregate. The general facility of polynuclear metal species in accepting or donating electrons (i.e. electronic amphoteric behaviour) is related to their orbital structure and their ready interaction, involving a variety of bonding patterns, with simple inorganic molecules is reviewed. The considerable facility for hydrogen abstraction is emphasized and the chemistry of the substituted hydridocarbonyls described. For simple alkenes and alkynes, a number of bonding patterns have been established, with bonding to two or three metal atoms of the cluster unit. For alkenes, interaction occurs with fission of carbon-hydrogen bonds and the formation of metal-hydrogen and metal-carbon bonds. The relationship between the coordinated organic fragment and the product of interaction of the polynuclear groupings with alkynes is established. An analogy between the behaviour of these unsaturated species with polynuclear carbonyls and the interaction of alkenes and alkynes with metal surfaces is emphasized.
\end{abstract}

The reactivity of organic species coordinated to a metal centre has been a point of considerable activity over the past decade. These studies have illustrated that major modifications in the stability and structure of organic grouping may occur on coordination to a metal centre. As far as the structure and reactivity are concerned studies of this kind do pose the question of how far the coordination of a metal ion to an organic group may be viewed as a minor perturbation of an organic system, and this seems especially true when organic $\pi$ electron systems are involved in the bonding pattern. 


\section{J. LEWIS AND B. F. G. JOHNSON}

The extension of these studies to include the interaction of an unsaturated molecule with more than one metal centre has not been extensively investigated. Such studies that are available, however, suggest, especially in systems where the metal centres are part of a metal-metal bonding network, that they may provide potential analogies for the study of the structure and reactivity of organic species on metal surfaces or with heterogeneous catalytic systems. The nature of the bonding of even simple organic molecules, such as ethylene on a metal surface, is not well understood and has only recently been subjected to detailed studies by techniques such as ESCA ${ }^{1}$. One of the main lines of structural evidence available arises from studies on the change in the infra-red spectra of the species on interaction with a metal surface and has established the formation of metal-hydrogen, metal-carbon interactions and a major modification to the $\pi$-electron distribution within the carbon-carbon bond ${ }^{2}$. It is of obvious interest to establish how simple organic molecules interact with a multimetal system, and contrast this behaviour with that of a single metal centre, although the obvious danger of drawing too close an analogy with metal surfaces must be recognized. This paper sets out to establish some of the variation in bonding patterns and to consider the general chemistry of both simple inorganic and organic molecules with cluster units in which metal-metal bonding occurs.

A convenient system to illustrate these points is provided by some of the Group VIII carbonyls. The systems discussed will be mainly the trinuclear dodecacarbonyls of iron, ruthenium and osmium, as these provide the simplest unit in which a multibonding centre may be expected. The main emphasis of the discussion will be directed towards three aspects of the chemistry, viz.

(i) The nature of the bonding and the fluxionality exhibited by the polynuclear carbonyls of Group VIII;

(ii) The variation in the reactivity of the trinuclear clusters to inorganic donors;

(iii) The structure and reactivity of simple unsaturated organic groups with the polynuclear carbonyls.

Obviously it is not possible to cover all aspects of these subjects in detail, but it is hoped that the following will provide an outline of some of the more important features of this chemistry.

\section{(I) STRUCTURE AND FLUXIONALITY OF POLYNUCLEAR METAL CARBONYLS}

\section{(a) Structure}

The known polynuclear carbonyls of the Group VIII elements are given in Table $1^{3}$. The preparation of the higher polynuclear carbonyls of osmium was established recently and involves the thermal decomposition of the trinuclear dodecacarbonyl, which gives the required carbonyls in high yield ${ }^{4}$.

$$
\mathrm{Os}_{3}(\mathrm{CO})_{12} \stackrel{195^{\circ} \mathrm{C}}{\longrightarrow} \mathrm{Os}_{5}(\mathrm{CO})_{16}+\mathrm{Os}_{6}(\mathrm{CO})_{18}+\mathrm{Os}_{7}(\mathrm{CO})_{21}+\mathrm{Os}_{8}(\mathrm{CO})_{23}
$$

The production of these carbonyls illustrates the important property of the 
polynuclear carbonyls of the second and third row elements of yielding higher polynuclear aggregates on controlled thermal decomposition. The identification of species of this nature is primarily accomplished from mass spectroscopic techniques and imposes, at the moment, a limitation to the establishment of clusters of much greater size.

Table 1. Carbonyls of Group VIII elements

\begin{tabular}{|c|c|c|}
\hline $\begin{array}{l}\mathrm{Fe}(\mathrm{CO})_{5} \\
\mathrm{Fe}_{2}(\mathrm{CO})_{9} \\
\mathrm{Fe}_{3}(\mathrm{CO})_{12}\end{array}$ & $\begin{array}{l}\mathrm{Co}_{2}(\mathrm{CO})_{8} \\
\mathrm{Co}_{4}(\mathrm{CO})_{12} \\
\mathrm{Co}_{6}(\mathrm{CO})_{16}\end{array}$ & $\mathrm{Ni}(\mathrm{CO})_{4}$ \\
\hline $\begin{array}{l}\mathrm{Ru}(\mathrm{CO})_{5} \\
\mathrm{Ru}_{3}(\mathrm{CO})_{12}\end{array}$ & $\begin{array}{l}{\left[\mathrm{Rh}_{2}(\mathrm{CO})_{8}\right]} \\
\mathrm{Rh}_{4}(\mathrm{CO})_{12} \\
\mathrm{Rh}_{6}(\mathrm{CO})_{16}\end{array}$ & - \\
\hline $\begin{array}{l}\mathrm{Os}(\mathrm{CO})_{5} \\
\mathrm{Os}_{2}(\mathrm{CO})_{9} \\
\mathrm{Os}_{3}(\mathrm{CO})_{12} \\
\mathrm{Os}_{5}(\mathrm{CO})_{16} \\
\mathrm{Os}_{6}(\mathrm{CO})_{18} \\
\mathrm{Os}_{7}(\mathrm{CO})_{21} \\
\mathrm{Os}_{8}(\mathrm{CO})_{23}\end{array}$ & $\begin{array}{l}\mathrm{Ir}_{4}(\mathrm{CO})_{12} \\
\mathrm{Ir}_{6}(\mathrm{CO})_{16}\end{array}$ & - \\
\hline
\end{tabular}

The rationalization of the structure of these carbonyl clusters provides a good example of the necessity to consider the cluster unit in toto, rather than the individual electronic requirements of single metal atoms. The current rationale of the structures of simple polynuclear carbonyl systems is based on the donation of two electrons by each carbonyl group to the metal cluster system and the attainment of the inert gas configuration for each metal atom within the cluster by the formation of metal-metal bonds. This process has considerable success in predicting the formula and structural details of both the carbonyls and their derivatives. The first real ambiguity arose in establishing the most stable electronic structure for the $\left[\mathrm{Rh}_{6}(\mathrm{CO})_{16}\right]$ cluster unit, which was designated ${ }^{5}$ as corresponding to an 84,86 or 88 electron system, i.e. the units $\left[\mathrm{Rh}_{6}(\mathrm{CO})_{16}\right]^{2+}, \mathrm{Rh}_{6}(\mathrm{CO})_{16},\left[\mathrm{Rh}_{6}(\mathrm{CO})_{16}\right]^{2-}$. For the more complex systems it is also possible to consider more than one structural type in which each individual metal atom fulfils the inert gas rule, by varying the nature and number of electrons involved in the metal-metal bond from a given metal atom.

A convenient correlation of the potential structures has been suggested by Wade, based on the number of electrons involved in bonding within the metal cluster in a manner used to rationalize the structure of the higher boron hydride derivatives ${ }^{6}$. The basic analogy between the two fields arises from the utilization of three hybrid orbitals to the cluster bonding system, by each metal atom, as postulated for the boron hydrides series and the employment of the remaining six bonding orbitals of the initial nine orbitals $(5 d+1 s+3 p)$ on each metal atom for bonding ligand orbitals. The orbitals available for ligand bonding are then filled and the electron pairs remaining are considered to be involved in cluster bonding. The basic stereochemistry of the cluster is established from the number of electron pairs involved in the 


\section{J. LEWIS AND B. F. G. JOHNSON}

cluster bonding, such that $(n+1)$ pairs are associated with regular polyhedra with $n$ vertices; thus, five skeletal bonding pairs are associated with a tetrahedral arrangement, six with a trigonal bipyramid and seven with a regular octahedron. For a system in which the number of skeletal electron pairs is the same as the number of metal atoms in the cluster, the structure is related to the metal cluster of one metal atom less and one face of the polyhedra is capped by the remaining metal atom. Using the above procedure, both $\mathrm{Os}_{5}(\mathrm{CO})_{16}$ and $\mathrm{Os}_{6}(\mathrm{CO})_{18}$ involve six skeletal bond pairs. The predicted structure of the $\mathrm{Os}_{6}(\mathrm{CO})_{18}$ species on the Wade theory would, therefore, be based on a trigonal bipyramid with one face capped by an osmium unit, i.e. an octahedron of $C_{2 \mathrm{v}}$ symmetry. The regular octahedral symmetry, $O_{\mathrm{h}}$, which would be consistent with the inert gas configuration, would not be expected. The addition of two electrons to the $\mathrm{Os}_{6}(\mathrm{CO})_{18}$ unit would increase the cluster bonding electron pairs to seven and Wade's theory would predict octahedral symmetry, $O_{h}$, for the resulting ion $\left[\mathrm{Os}_{6}(\mathrm{CO})_{18}\right]^{2-}$.

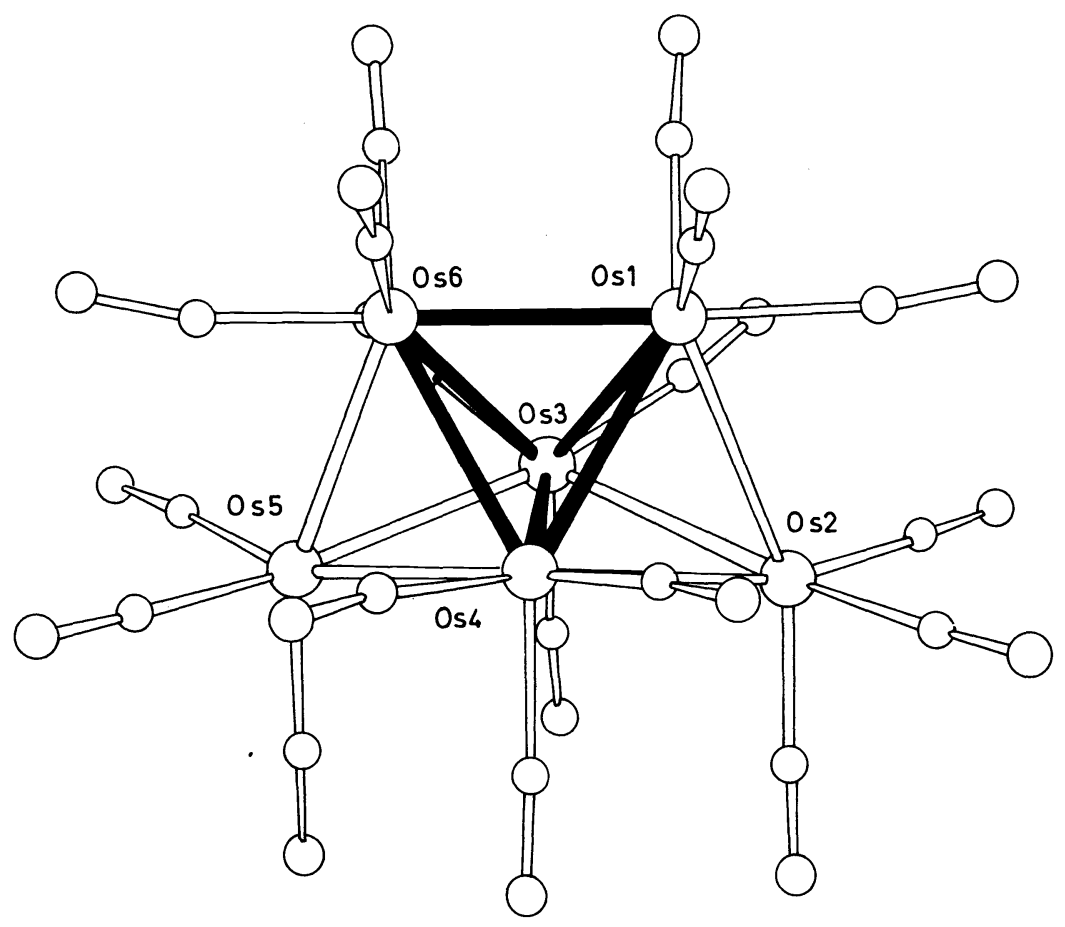

Figure 1

In agreement with the above, the structure of the compound $\mathrm{Os}_{6}(\mathrm{CO})_{18}$, has been shown ${ }^{7}$ to involve a capped trigonal bipyramid (Figure 1). Reaction of the complex with activated zinc yields the anion $\left[\mathrm{Os}_{6}(\mathrm{CO})_{18}\right]^{2-}$ which has a very simple infra-red spectrum consistent with octahedral symmetry, $O_{\mathrm{h}}{ }^{8}$. The structure of the carbonyl $\mathrm{Os}_{7}(\mathrm{HO})_{21}$ is also consistent with this 
theory, the structure being established as an octahedron of osmium atoms of $O_{\mathrm{h}}$ symmetry, with one face capped by the remaining osmium atom? These structural data emphasize the sensitivity of the basic skeletal structures of the metal systems in these polynuclear carbonyls to the electronic structure of the cluster bonding system and also imply a facility for these systems to accept and donate electrons from the skeletal metal framework, which may relate to pure metal systems. The facility of polynuclear aggregates to act as electron 'sinks' has been well recognized, and in particular the studies of Dahl and co-workers have established this electronic amphoteric behaviour for a variety of trinuclear and tetranuclear metal clusters; extensive structural studies on the variation in metal-metal bond distances and geometry have been rationalized in terms of the electron acceptor-donor power of the cluster units ${ }^{9-12}$.

Although Wade's theory is empirical in nature, it has a general utility in dealing with structural data in this type of compound. The theory has been given some mathematical foundation by Mingos who has shown, using a Wolfsberg-Helmholtz approximation, that for the carbonyl anion $\left[\mathrm{Co}_{6}\right.$ $\left.(\mathrm{CO})_{14}\right]^{2-}$ the metal cluster orbitals have a very high proportion of $s$ and $p$ character being of a similar character to that employed in the $\mathrm{B}_{6} \mathrm{H}_{6}^{2-}$ ion. This work ${ }^{13}$ also emphasizes that the highest filled molecular orbitals are .weakly antibonding with regard to the metal-metal framework $\dagger$.

\section{(b) Fluxionality}

Previous work, particularly that using infra-red and ${ }^{1} \mathrm{H}$ n.m.r. spectroscopy, has illustrated that many carbonyls and substituted carbonyls have structures in solution which differ significantly from that observed in the solid state $^{14,15}$. In many cases, in solutions, an equilibrium exists between a number of different structural forms. In addition, the fluxional nature exhibited by many organic molecules coordinated to metal carbonyl fragments has been established primarily from the study of ${ }^{31} \mathrm{P}$ and ${ }^{1} \mathrm{H}$ n.m.r. spectroscopy. With the advent of ${ }^{13} \mathrm{C}$ n.m.r. spectroscopy it has become possible to study the related problem for the metal carbonyl and, in particular, to establish the role of the carbonyl groups in the mechanism of these fluxional processes. The following account emphasizes the dynamic nature of molecules in solution and the ready mobility, on the n.m.r. time scale, of carbonyl groups within these molecules.

It is perhaps pertinent at this stage to emphasize two differences between ${ }^{1} \mathrm{H}$ and ${ }^{13} \mathrm{C}$ n.m.r. spectroscopy. As the nuclear relaxation times of the two nuclei may differ considerably, in contrast to the behaviour for proton systems the probability of using the intensity of the ${ }^{13} \mathrm{C}$ signal as a measure of relative concentration of carbonyls within different environments is difficult. In particular the carbon signal is very sensitive to the nature of the nuclei directly bonded to the carbon and, in unfavourable circumstances, it is possible that no signal will be detected. This problem has been overcome, in part, by the use of paramagnetic relaxation reagents, such as chromium

$\dagger$ The essence of the 'Wade' theory is that the highest filled and lowest empty molecular orbitals are primarily cluster bonding orbitals, with the metal-ligand bonding orbitals at very low energy. 
J. LEWIS AND B. F. G. JOHNSON

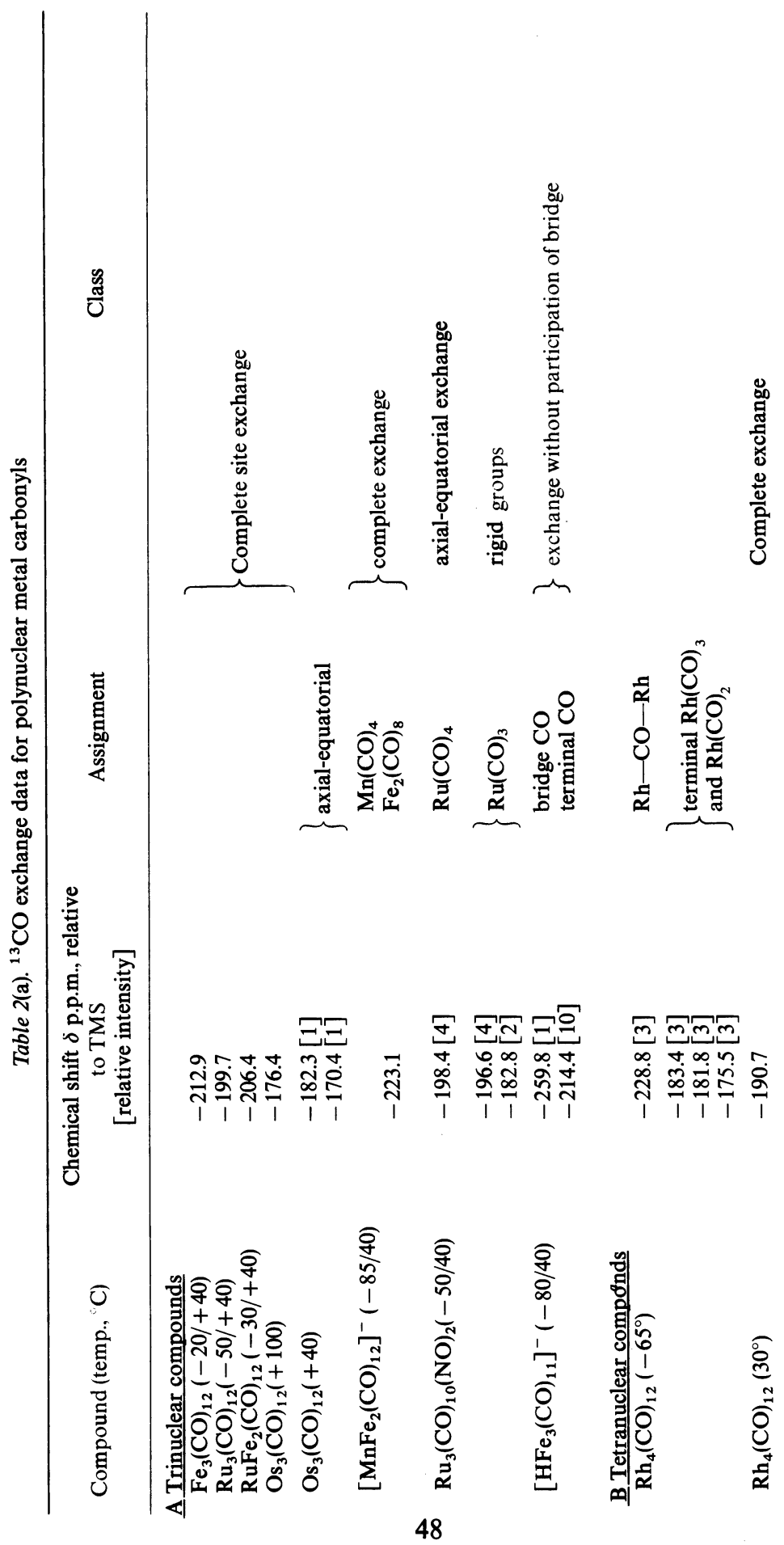



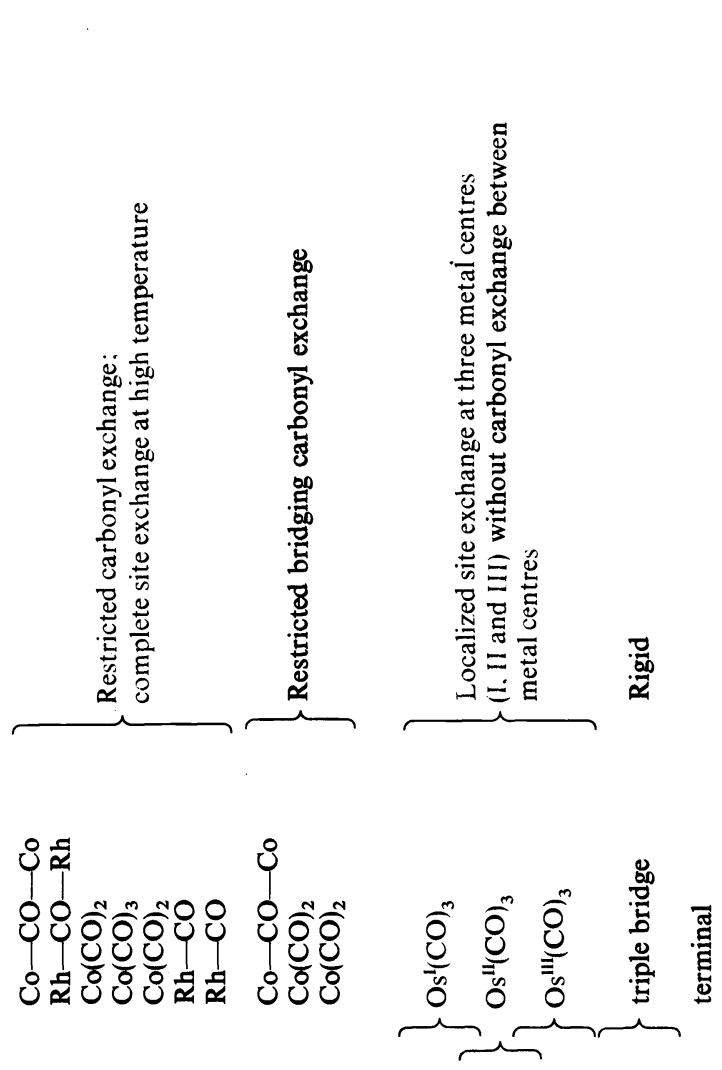

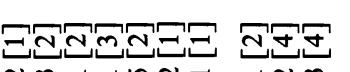
กุต

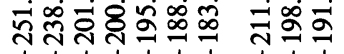

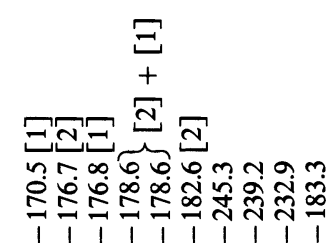

ฟ
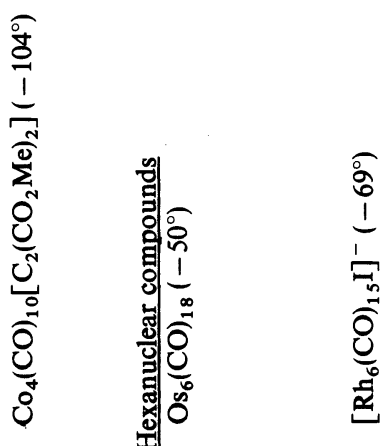
J. LEWIS AND B. F. G. JOHNSON

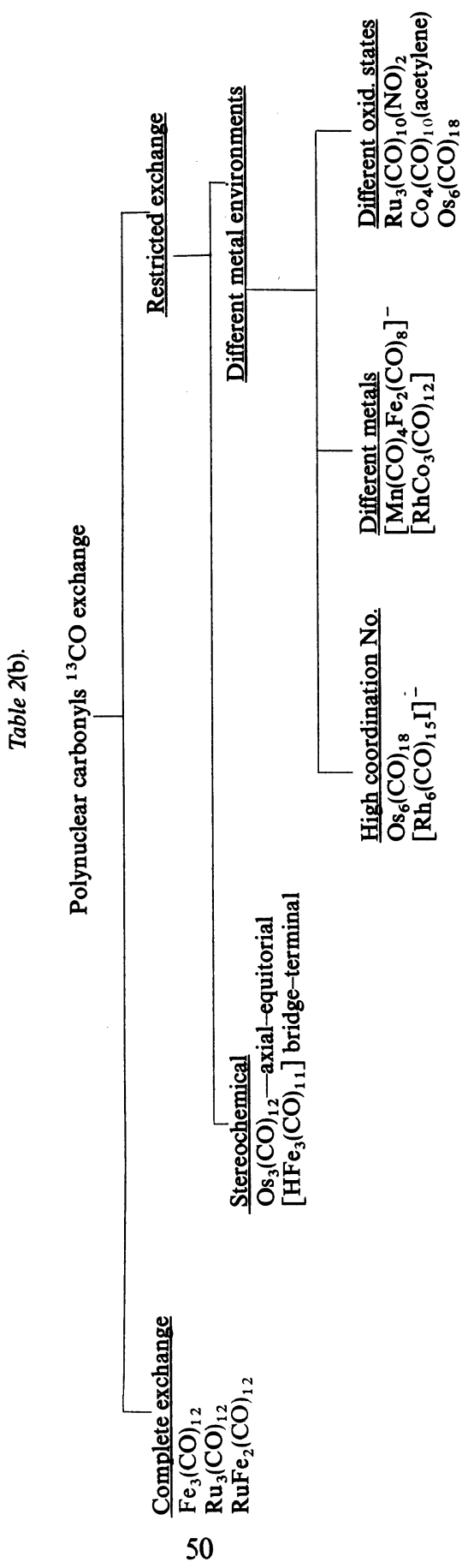




\section{POLYNUCLEAR CARBONYLS OF GROUP VIII}

$\beta$-diketonate complexes ${ }^{16}$. As these possibly operate by a dipolar mechanism, the intensity of the peaks may vary depending upon the structure of the molecule. In metal systems, this possibility may be further accentuated by the presence of nuclei which have large quadrupole moments such as cobalt and manganese.

Using Fourier transform techniques it is possible to obtain the spectra of many of the molecules using the ${ }^{13} \mathrm{C}$ present in natural abundance. In contrast to the behaviour of protonic systems this normally leads to a relatively simple spectrum as ${ }^{13} \mathrm{C}-{ }^{13} \mathrm{C}$ coupling is eliminated. It is convenient to relate such spectra to those of enriched ${ }^{13} \mathrm{C}$ samples when the appropriate coupling may be observed and utilized for assignment purposes. With the platinum and rhodium compounds there is the further advantage that as both these metals contain atoms with nuclear spins of $\frac{1}{2}$, significant metalcarbon coupling may be anticipated. As discussed below, this may be used as a useful probe in elucidating the mechanism of fluxionality in these systems. Table 2 contains data on the temperature variation of the spectra of a number of polynuclear carbonyls and substituted derivatives. It is convenient to discuss these data in terms of the molecularity of the metal in the carbonyl species.

\section{(I) Tetranuclear carbonyls}

The fluxional nature of metal carbonyl derivatives may be readily illustrated from ${ }^{13} \mathrm{C}$ n.m.r. studies on $\mathrm{Rh}_{4}(\mathrm{CO})_{12}$. The structure of the carbonyl in the solid is given in Figure 2, and implies four different environments for

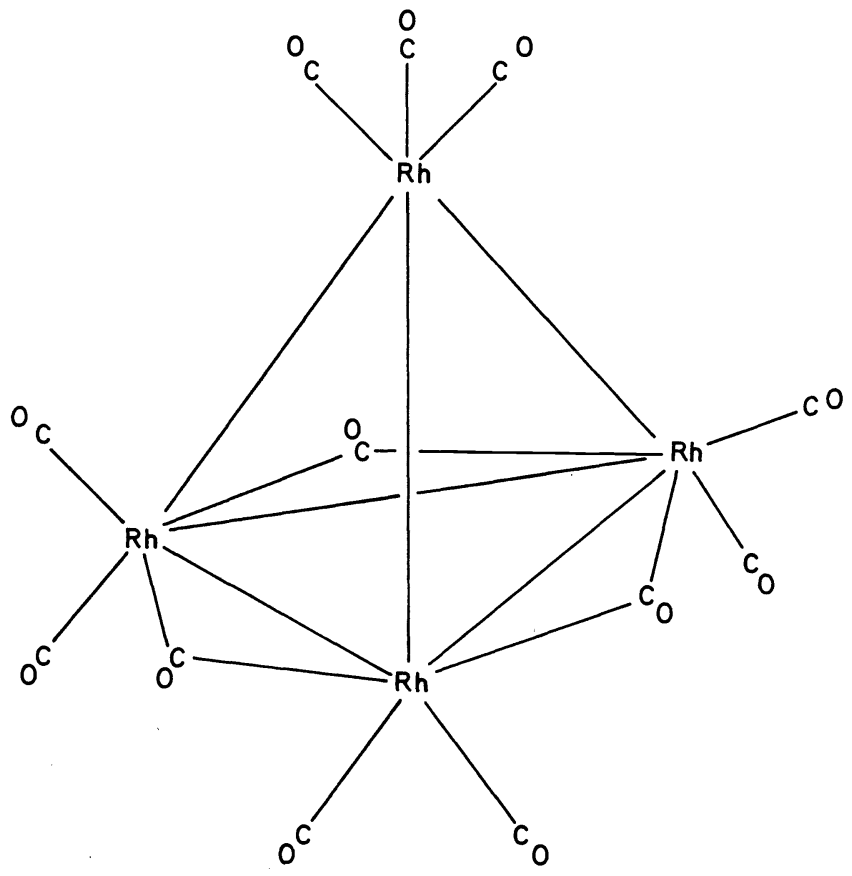

Figure 2 


\section{J. LEWIS AND B. F. G. JOHNSON}

the carbonyl group. As stated above, the rhodium nucleus is a spin $\frac{1}{2}$ system in 100 per cent abundance, and so coupling between the rhodium and the carbon of the carbonyl groups may be expected. The ${ }^{13} \mathrm{C} \mathrm{n}$.m.r. spectra of a partially enriched sample ( $\sim 15$ per cent), between $0^{\circ}$ and $60^{\circ} \mathrm{C}$, shows a quintet structure consistent with the scrambling of the carbonyl groups between the four rhodium centres and coupling to all four rhodium nuclei ${ }^{20}$. A study of the low temperature ${ }^{13} \mathrm{C}$ n.m.r. spectra (Figure 3 ) exhibited, below $-65^{\circ} \mathrm{C}$, four resonances of equal intensity which is compatible with the solid state structure in Figure $2^{18}$. In particular, the bridging carbonyl resonance was identified as this occurred as a triplet, coupled to two rhodium atoms. Using ${ }^{13} \mathrm{CO}$ enriched samples, it was possible to identify the chemical shifts of the three remaining carbonyl environments utilizing ${ }^{13} \mathrm{C}-{ }^{13} \mathrm{C}$ coupling data. The spectra were recorded at temperature intervals up to the coalescence temperature at $-5 \pm 5^{\circ}$. The collapse of the slow exchange spectrum was substantially uniform, indicating that there was no site selectivity involved in the scrambling process and may be rationalized in terms of uniform bond breaking of the bridging carbonyls to yield a symmetrical intermediate of $T_{\mathrm{d}}$ symmetry.

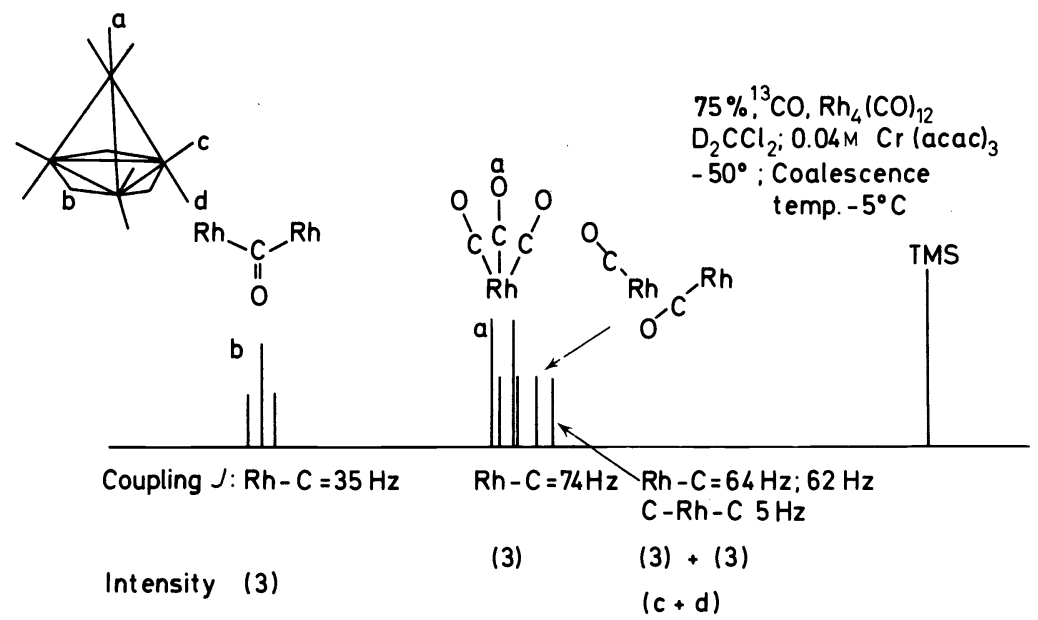

Figure 3

Extension of this work to the related mixed carbonyl ${ }^{19} \mathrm{RhCo}_{3}(\mathrm{CO})_{12}$, the preparation of which was recently reported by Chini and co-workers ${ }^{21}$, illustrates an alternative mechanism involving a concerted bridge breaking and making process. The low temperature ${ }^{13} \mathrm{C} \mathrm{n}$.m.r. spectra of the mixed carbonyl [Figure 4] is completely consistent with the structure proposed by Chini et al. ${ }^{21}$. The presence of the rhodium atom in the bridging carbonyl plane was established by the existence of two sets of carbonyl absorptions in the bridging region, one being split by the rhodium nuclear spin. The inequivalence of the two terminal carbonyls on the rhodium was also confirmed and their identity established from the rhodium coupling. On raising 
POLYNUCLEAR CARBONYLS OF GROUP VIII
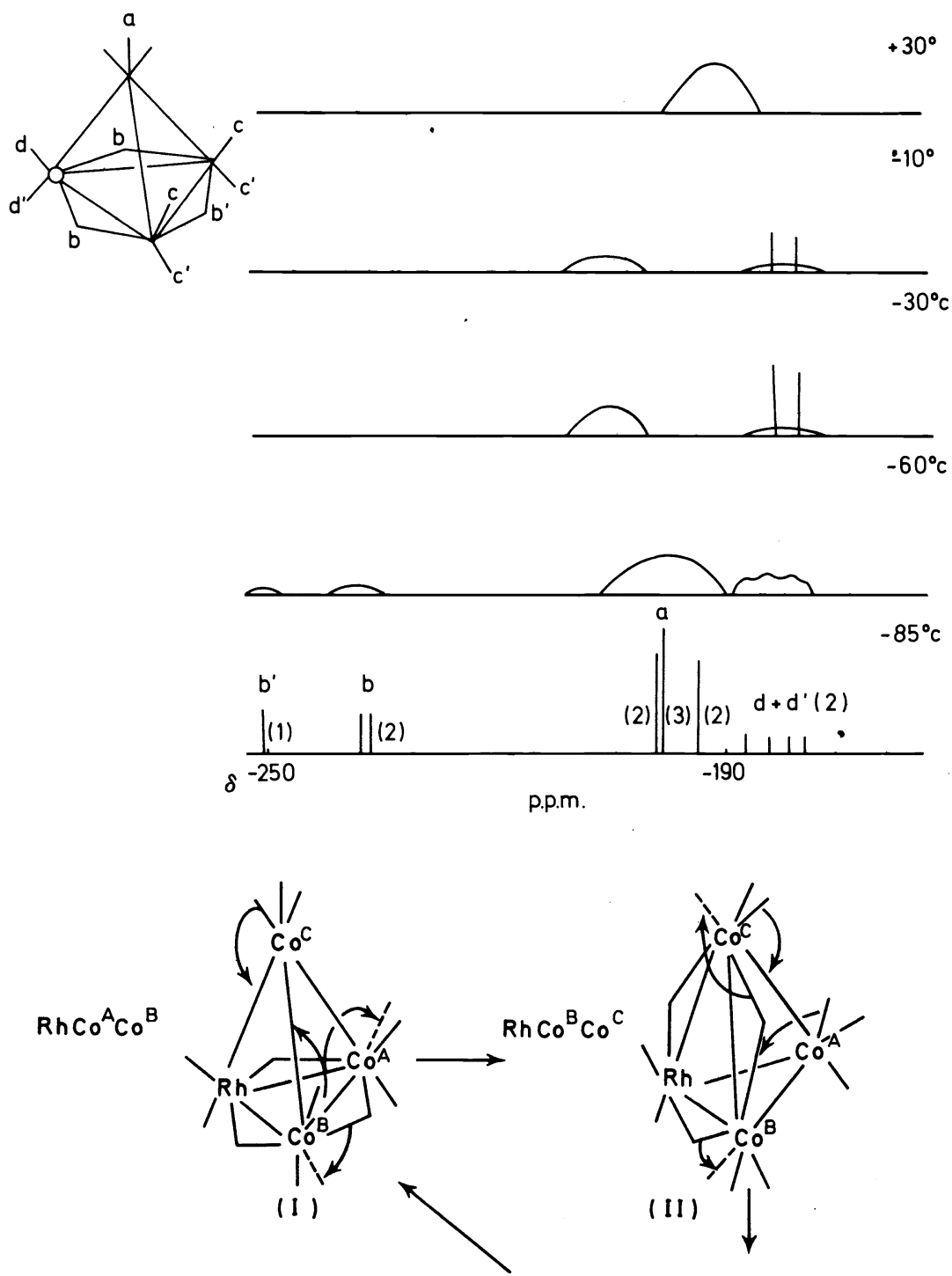

Figure 4

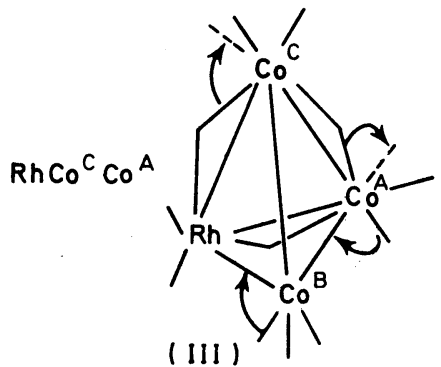




\section{J. LEWIS AND B. F. G. JOHNSON}

the temperature, the resonance attributed to the bridging carbonyls and the terminal carbonyls of the cobalt coalesce, whilst the inequivalence of the two terminal carbonyls associated with the rhodium disappears but preserves their unique bonding character to the rhodium as implied by the maintenance of the $\mathrm{Rh}-{ }^{13} \mathrm{C}$ coupling. At higher temperatures this inequivalence is removed and a single signal, due to exchange of the carbonyl groups between all available sites, is observed.

These spectral data may be interpreted in terms of a concerted bridge making and breaking mechanism which allows the equilibration of the bridging carbonyl groups and the terminal cobalt-carbonyl groups. A symmetrical intermediate of the form considered for the $\mathrm{Rh}_{4}(\mathrm{CO})_{12}$ cannot apply as this would lead also to a scrambling of the terminal carbonyls bonded to the rhodium, which only occurs in the high temperature region. This emphasizes that carbonyl site exchange is not necessarily a one-stage process and may depend upon the variation and disposition of the metal within the carbonyl cluster.

A related exchange process has been suggested ${ }^{17}$ for the acetylene cobalt carbonyl cluster $\mathrm{Co}_{4}(\mathrm{CO})_{10}(\mathrm{RC} \equiv \mathrm{CR})$, in which the 'butterfly' bonding arrangement is suggested ${ }^{22}$ for the acetylene fragments to the metal cluster (Figure 5). The low temperature spectrum of this compound shows essentially two types of cobalt carbonyl environment consistent with the structure and a bridging carbonyl absorption. The inequivalence of the carbonyl groups on a given cobalt atom is also revealed in the spectra. The temperature variation of the spectra has been taken to indicate bridging carbonyl exchange with only one of the two cobalt-carbonyl atoms $\left(\mathrm{Co}^{\mathrm{A}}\right)$ and a stereospecific

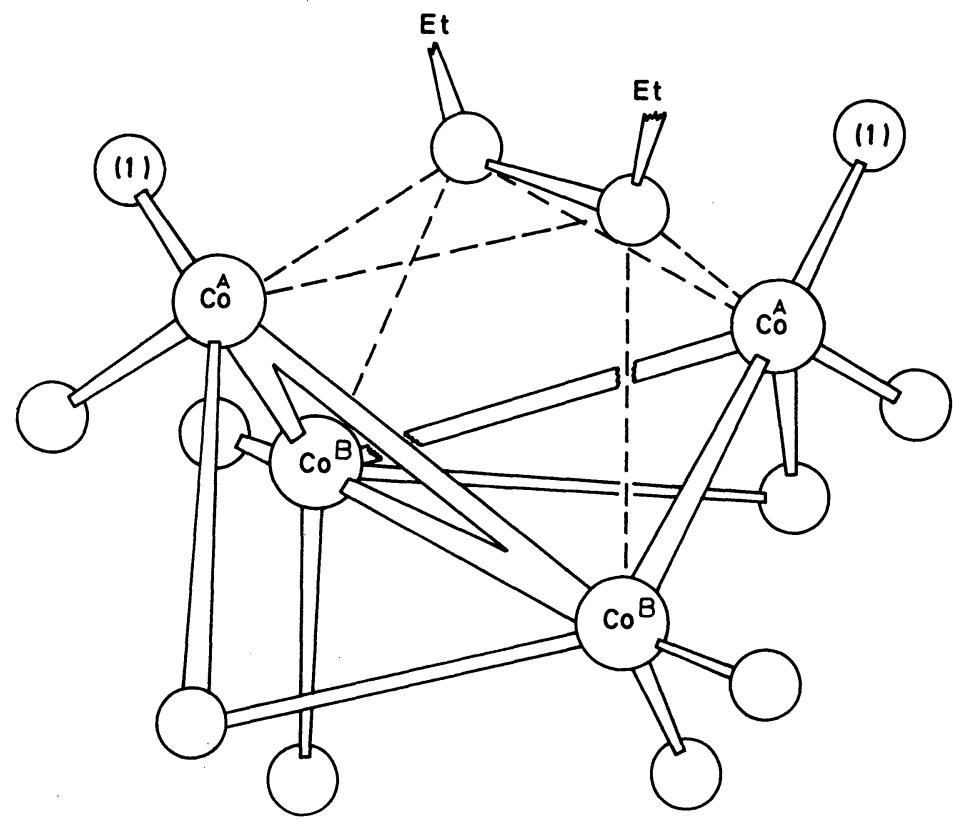

Figure 5 
exchange of the bridging carbonyl with only one $\left(\mathrm{CO}^{(\mathrm{l})}\right)$ of the two carbonyl sites of the exchanging cobalt system. This corresponds to a making of one carbonyl bridge along a cobalt-cobalt bond $\left(\mathrm{Co}^{\mathrm{A}}-\mathrm{Co}^{\mathrm{B}}\right)$ whilst the related bridging carbonyl group is breaking. Thus, in the complex, the inequivalence of the two cobalt situations is recognized in the mechanistic process and the stereochemical inequivalence of the carbonyl groups on a given metal centre is maintained during the terminal-bridge-exchange process.

\section{(II) Trinuclear carbonyls}

For the trinuclear carbonyls $\mathrm{M}_{3}(\mathrm{CO})_{12}(\mathrm{M}=\mathrm{Fe}, \mathrm{Ru}, \mathrm{Os})$, the mixed carbonyl, $\operatorname{RuFe}_{2}(\mathrm{CO})_{12}$, and the carbonyl-nitrosyl $\mathrm{Ru}_{3}(\mathrm{CO})_{9}(\mathrm{NO})_{2}$, n.m.r. data are reported in Table 2 . A single resonance is observed down to $-40^{\circ} \mathrm{C}$

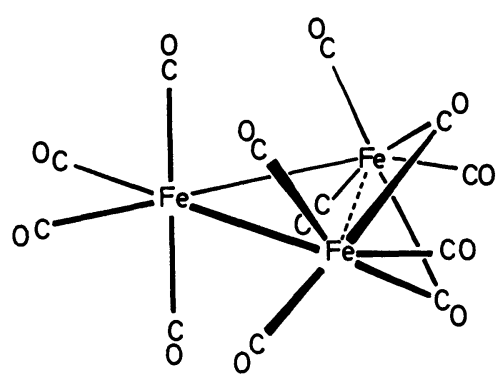

$\mathrm{Fe}_{3}(\mathrm{CO})_{12}$

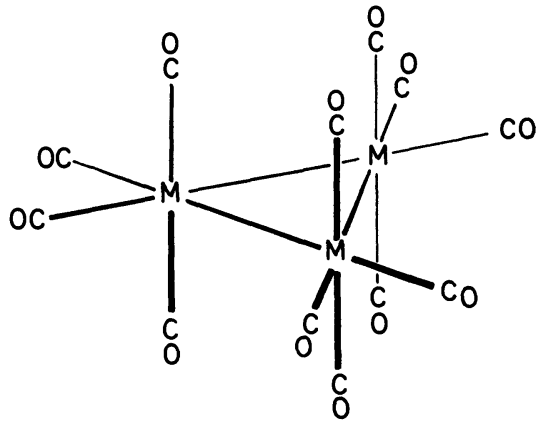

$M_{3}(\mathrm{CO})_{12}(M=R u$ or Os)

Figure 6

(at which temperature solubility problems arise) for the iron and ruthenium dodecacarbonyls, indicating rapid bridge-terminal exchange within the iron complex and rapid equatorial-axial exchange for the terminal carbonyl groups of both the iron and ruthenium complexes (Figure 6, left and right). For the osmium derivative, separation into two broad singlets is observed at low temperatures corresponding to axial and equatorial environments of the carbonyl groups (Figure 6). The higher energy of activation for this exchange process in the case of osmium is consistent with the trends normally experienced within a transition metal triad. The behaviour of the $\mathrm{Ru}_{3}(\mathrm{CO})_{10^{-}}$ (NO) ${ }_{2}$ contrasts with that observed for the parent carbonyl and exhibits a different exchange process to that observed in the tetranuclear $R h_{4}$ species. The ${ }^{13} \mathrm{C}$ n.m.r. spectra show virtually no temperature variation between $-50^{\circ}$ and $+40^{\circ}$ and exhibit three absorption bands in the terminal carbonyl region, with an intensity ratio of $2: 2: 1$. The structure of the compound is given in Figure 7, from which four groups of carbonyl absorptions would have been anticipated; two groups of carbonyls associated with the two ruthenium atoms involved in the nitrosyl bridge and two environments, the axial and equatorial distributions, for the unique ruthenium carbonyl groupings ${ }^{23}$. The data thus indicate a rapid exchange between the axial and equatorial sites of the unique ruthenium grouping whilst the two sets of carbonyls related to the other two ruthenium atoms remain stereochemically 
rigid. It would appear that in general if there is a significant difference in stereochemistry or formal oxidation state of metals within a metal cluster, the exchange between such metal centres is the highest energy process. This may reflect on the nature of the bridging carbonyl groups, which are normally invoked as an exchange pathway between carbonyl groups on different

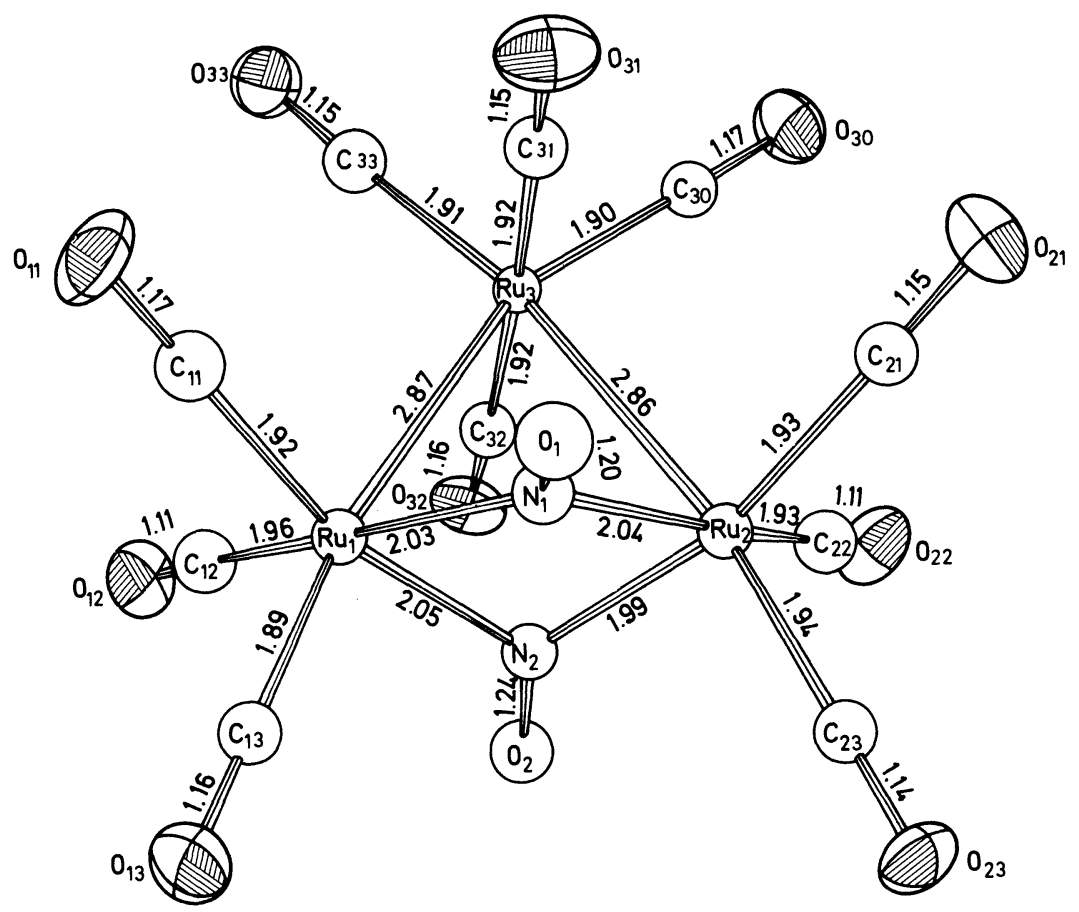

Figure 7

metal centres, and which may be very asymmetric when bridging between disparate metal atoms. In this respect, it is of interest to note that, in contrast to the fluxional behaviour of the bridge-terminal groups in the $\mathrm{Fe}_{3}(\mathrm{CO})_{12}$ system, for the related anion $\left[\mathrm{Fe}_{3}(\mathrm{CO})_{11} \mathrm{H}\right]^{-}$, in which one of the bridging carbonyls is replaced by a hydrido-bridge ${ }^{24}$, two signals are observed, one in the bridging and one in the terminal carbonyl region, implying terminal exchange without exchange of the bridge carbonyl group. This indicates a bridging intermediate in which carbonyl bridge formation occurs across the edge of the metal triangle that does not involve the hydride bridge and a stereochemical rigidity to both the hydride and carbonyl group of the bridging system.

\section{(III) Hexanuclear carbonyls}

A study of the hexanuclear carbonyl, $\mathrm{Os}_{6}(\mathrm{CO})_{18}$, provides a further example of the lack of exchange of carbonyls between stereochemically different metal centres, whilst exchange around a given metal centre is facile. The 
structure of the carbonyl (Figure 1) indicates three types of osmium metal environment and two classes of carbonyl grouping on each metal centre ${ }^{7}$. The ${ }^{13} \mathrm{CO}$ spectrum of an enriched ${ }^{13} \mathrm{C}$ sample was obtained at $-50^{\circ} \mathrm{C}$ and was consistent with the structure obtained for the solid. Three sets of signals, corresponding to the three metal environments were obtained and each was separated into a pair of signals, in the ratio of $2: 1$, corresponding to the variation in the local carbonyl environment. On allowing the temperature to rise, each set of peaks on a given metal centre coalesced to a singlet at three different temperatures, indicating a different energy of activation for the stereochemical equilibration process of the carbonyl groups at the three osmium sites. Up to the highest temperatures studied $\left(\sim 100^{\circ}\right)$ no exchange between the metal centres was indicated.

The results obtained for the above compounds reflect on the dynamic nature of the carbonyl groups within these compounds at normal temperatures. However, chemically rigid systems have been observed in polynuclear aggregates; thus Chini and co-workers recently reported ${ }^{25}$ the spectrum of the anion $\left[\mathrm{Rh}_{6}(\mathrm{CO})_{15}\right]_{2}^{2-}$, in which two sets of rhodium octahedra are combined via carbonyl bridging groups. The detailed spectrum could be assigned in terms of a rigid structure, equivalent to that obtained for the structure in the solid state. Variation of the temperature up to $25^{\circ}$ showed no indication of carbonyl site exchange even on the same metal centre. We have observed ${ }^{80}$ a similar phenomenon for the anion $\left[\mathrm{Rh}_{6}(\mathrm{CO})_{15} \mathrm{I}\right]^{-}$, which appears to be stereochemically rigid up to the maximum temperature studied of $30^{\circ}$. In these systems, with three-centre carbonyl groups, it is important that there are three equivalent, three-centre groups associated within the metal framework to allow exchange to occur via an intermediate in which there is no electronic disparity between metal centres, the general criterion for exchange within metal cluster systems being considered to proceed by mechanisms that do not violate the electronic requirements of the metal atoms. This may be formulated ${ }^{79}$ in what may be termed the 'Cotton principle' viz. 'Carbonyl scrambling processes (i.e. those in which $\mathrm{CO}$ groups pass from one metal atom to another including bridge-terminal exchange) occur only by pathways in which the electron sufficiency and electron neutrality of all metal atoms is continuously maintained'.

For the rhodium anions, in addition to number and types of three-centred carbonyl groups, the effective coordination number of the metal atoms within the cluster unit is high. The formation of a terminal to bridging carbonyl group occurs with an increase in the coordination number of metal atoms within the cluster unit and would therefore be less probable with increasing initial coordination number of the metal centres involved.

\section{(II) VARIATION IN REACTIVITY OF SOME TRINUCLEAR CLUSTERS TO INORGANIC DONORS}

The trinuclear dodecacarbonyls of iron, ruthenium and osmium undergo a variety of substitution and addition reactions producing compounds in which the trinuclear cluster is maintained. The stability of the cluster unit increases with increasing atomic weight of the metal. This may be associated with the enhanced kinetic stability normally found with compounds 
of the third row elements and/or the greater strength of the metal-metal bonds with increasing atomic weight of the metal. The determination of metal-metal bond energies in metal clusters has been a point of interest for some time, and a variety of data, such as bond lengths, force constants or fragmentation patterns in mass spectroscopy, have been employed to examine their variation with position of the metal in the transition series. Table 3 contains the most recent data for the bond enthalpies of metal-metal

Table 3. Bond enthalpy in metal carbonyls (values in $\mathrm{kcal} \mathrm{mol}^{-1}$ )

\begin{tabular}{lccccc}
\hline & $\mathrm{Cr}$ & $\mathrm{Mn}$ & $\mathrm{Fe}$ & $\mathrm{Co}$ & $\mathrm{Ni}$ \\
Metal & - & 16 & 19.2 & 22 & - \\
Carbonyl & 25.7 & 23.7 & 28.1 & 32.5 & 35.1 \\
Methyl & - & 27.9 & - & - & - \\
\hline \multirow{2}{*}{ Metal } & $\mathrm{Mo}$ & $\mathrm{Tc}$ & $\mathrm{Ru}$ & $\mathrm{Rh}$ & \\
Carbonyl & 36.3 & - & 28 & 26.8 & \\
\hline & $\mathrm{W}$ & $\mathrm{Re}$ & $\mathrm{Os}$ & $\mathrm{Ir}$ & \\
Metal & - & 30.5 & 31.1 & 31 & \\
Carbonyl & 42.6 & 44.8 & 45.8 & 45.3 & \\
Methyl & - & 53.2 & - & - & \\
\hline
\end{tabular}

bonds in metal carbonyl cluster systems, with the related values of the bond enthalpies of the metal-carbon bond for the terminal carbonyl group $^{26}$. It is significant to note that the increase in stability of metalmetal bonds as implied by the previous considerations, on descending a triad, is paralleled by an increase in the stability of the metal-carbon bonds. This must complicate any discussion of the stability of metal cluster units solely in terms of the enhancement in the stability of the metal-metal bonds on descending the triad. Nevertheless, there is a marked contrast between the behaviour of the dodecacarbonyl of iron, which generally reacts with a large variety of ligands to yield mononuclear complexes, and triosmium dodecarbonyl which yields mainly trinuclear complexes.

For the trinuclear dodecacarbonyls, it has been suggested that the lowest empty molecular orbital is antibonding with respect to the metal-metal bonding framework, whilst the highest filled molecular orbital is weakly antibonding, although the absolute symmetry of the orbitals concerned is in debate $^{11,12}$. Thus the addition of electrons to the metal cluster will lead to a decrease in the metal-metal character of the unit, whilst removal of electrons should lead to an enhancement in the metal-metal bonding within the cluster. The general utility of cluster units as potential electron 'sinks' is one of the more rapidly developing aspects of polynuclear chemistry. The general chemical reactivity of the clusters is conveniently summarized in Table 4 and illustrates a range of reactions in which two metal centres are directly involved in bonding to the donor atoms. In the substitution reactions, two carbonyl groups, donating four electrons to the cluster, are replaced by a series of two, four and six electron donor systems. As noted above, it is significant that iron complexes are obtained only for substitution reactions 
POLYNUCLEAR CARBONYLS OF GROUP VIII

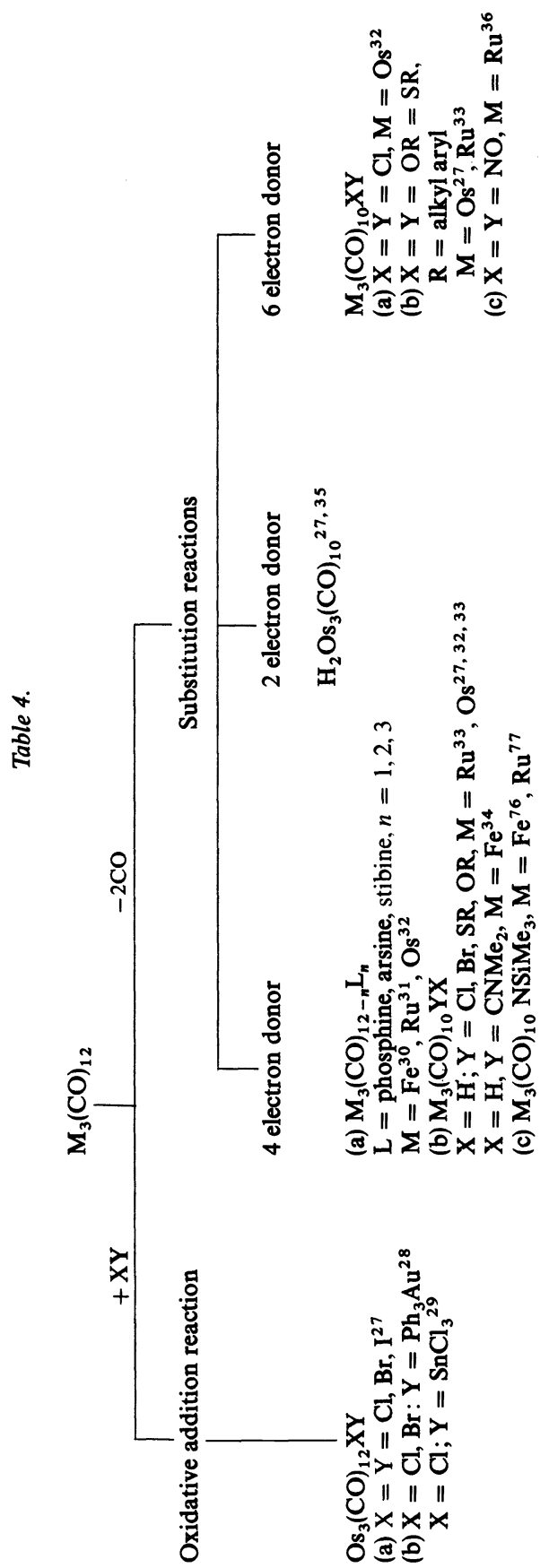




\section{J. LEWIS AND B. F. G. JOHNSON}

in which carbonyl groups are replaced with a similar class of ligands such as phosphines, and for one class of bridged species (vide infra), whilst a range of derivatives are readily obtained with osmium and ruthenium. In many instances, however, in contrast to the behaviour of the osmium system, the trinuclear ruthenium complexes appear as a minor component of the product distribution with a considerable preponderance of binuclear compounds.

The oxidation addition reactions, with halogens, lead to a linear polynuclear system for osmium, $\mathrm{Os}_{3}(\mathrm{CO})_{12} \mathrm{X}_{2}$, which on heating loses carbon monoxide to yield the triangular cluster unit $\mathrm{Os}_{3}(\mathrm{CO})_{10} \mathrm{X}_{2}$. The four electron donor system of the two carbonyl groups is replaced by the six electron donor grouping of the two halogen bridging atoms; as discussed above, this leads to an overall reduction in the bond order within the metal framework, as the electrons are added to a metal-metal antibonding orbital: conversely the replacement of the two carbonyl groups by two hydrogen atoms is equivalent to removal of electrons from the cluster and should lead to an increase in the bond order within the framework. As these substitution reactions occur with the formation of bridging species between two of the three metal atoms of the trinuclear series, it is not surprising that this variation in the metal bond character occurs in a localized manner. Figure 8
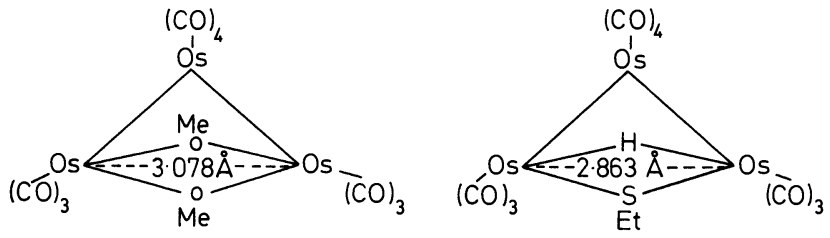

Figure 8

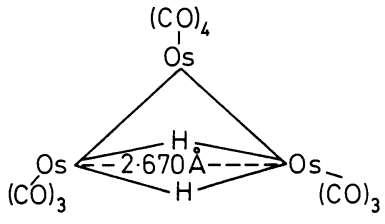

summarizes the bond length data obtained for a series of these bridged derivatives ${ }^{12}$. The overall metal-metal bonding varies from that of the parent carbonyl value ${ }^{37}$ of $2.85 \AA$ and is consistent with the formulation of the metal-metal bond orders as zero, single and double for the alkoxy, thiol and hydrido bridge systems respectively.

Of particular significance, in any consideration of these cluster units with organic systems, is the extreme facility with which hydrogen-metal bonds are formed from hydrogen-containing compounds. Kaesz was able to establish that these carbonyls even reacted with hydrogen gas to produce hydrido carbonyls in excellent yield ${ }^{35}$. For the ruthenium dodecacarbonyl the main product was the tetranuclear carbonyl $\mathrm{H}_{4} \mathrm{Ru}_{4}(\mathrm{CO})_{12}$. With the osmium compound the initial product was the trinuclear adduct $\mathrm{H}_{2} \mathrm{Os}_{3}$ $(\mathrm{CO})_{10}$ which yielded the tetranuclear compound under more forcing conditions. As will be discussed below, the ready formation of metal-hydrogen links dominates the organometallic chemistry of these derivatives and implies a high thermodynamic stability for metal-hydrogen bonds in this area of the periodic table.

The facile removal of hydrogen by these species also occurs in reactions with water ${ }^{38}$. Thus $\mathrm{Ru}_{3}(\mathrm{CO})_{12}$ reacts with water in a sealed tube at $135^{\circ} \mathrm{C}$ to 
give good yields of the polynuclear hydrido-carbonyl, $\mathrm{H}_{4} \mathrm{Ru}_{4}(\mathrm{CO})_{12}$. The related reaction with osmium is complicated by the formation of higher polynuclear carbonyls, reaction in a sealed tube at $230^{\circ} \mathrm{C}$ yielding a variety of products of varying molecular complexity. Thus the derivatives $\mathrm{H}(\mathrm{OH}) \mathrm{Os}_{3}-$ $(\mathrm{CO})_{10}, \mathrm{H}_{2} \mathrm{Os}_{4}(\mathrm{CO})_{13}$ and $\mathrm{H}_{4} \mathrm{Os}_{4}(\mathrm{CO})_{12}$ presumably arise from the reaction with $\mathrm{Os}_{3}(\mathrm{CO})_{12}$, whilst the other hydrido species $\mathrm{H}_{2} \mathrm{Os}_{5}(\mathrm{CO})_{16}, \mathrm{H}_{2} \mathrm{Os}_{5^{-}}$ $(\mathrm{CO})_{15}, \mathrm{H}_{2} \mathrm{Os}_{6}(\mathrm{CO})_{18}$ and $\mathrm{H}_{2} \mathrm{Os}_{7}(\mathrm{CO})_{19} \mathrm{C}$ arise from the intermediacy of the higher polynuclear carbonyls. The presence of small traces of water in reacting systems, particularly if carried out at high temperatures, may therefore produce intermediates of this nature and, as the hydrido-carbonyls generally are more reactive than the osmium dodecacarbonyl, this may lead to complications. It is, perhaps, pertinent to note that the above polynuclear carbonyl hydrides illustrate once more the facility of these more complex metal clusters to vary their electronic structure. The ligand electron contribution in the two hydrides, $\mathrm{H}_{2} \mathrm{Os}_{5}(\mathrm{CO})_{16}$ and $\mathrm{H}_{2} \mathrm{Os}_{5}(\mathrm{CO})_{15}$, differs by two electrons; a comparable arrangement occurs for $\mathrm{H}_{2} \mathrm{Os}_{6}(\mathrm{CO})_{18}$ and for the hydride $\mathrm{H}_{4} \mathrm{Os}_{6}(\mathrm{CO})_{16}$, which is obtained by reaction of $\mathrm{Os}_{6}(\mathrm{CO})_{18}$ with hydrogen gas ${ }^{39}$.

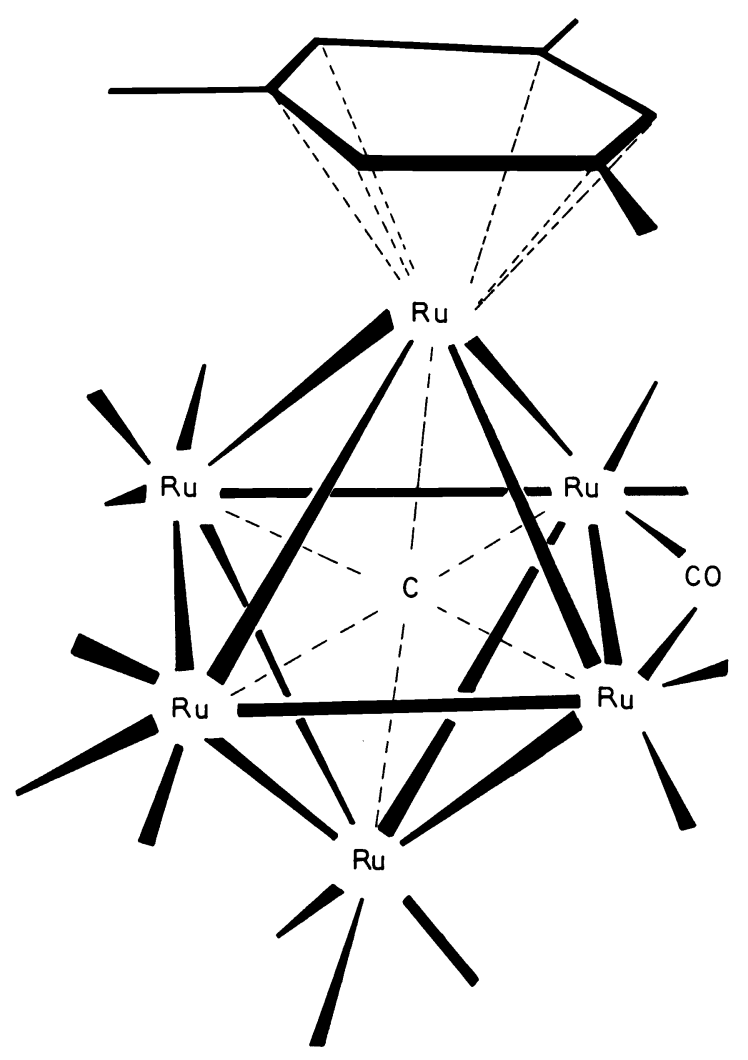

Figure 9 


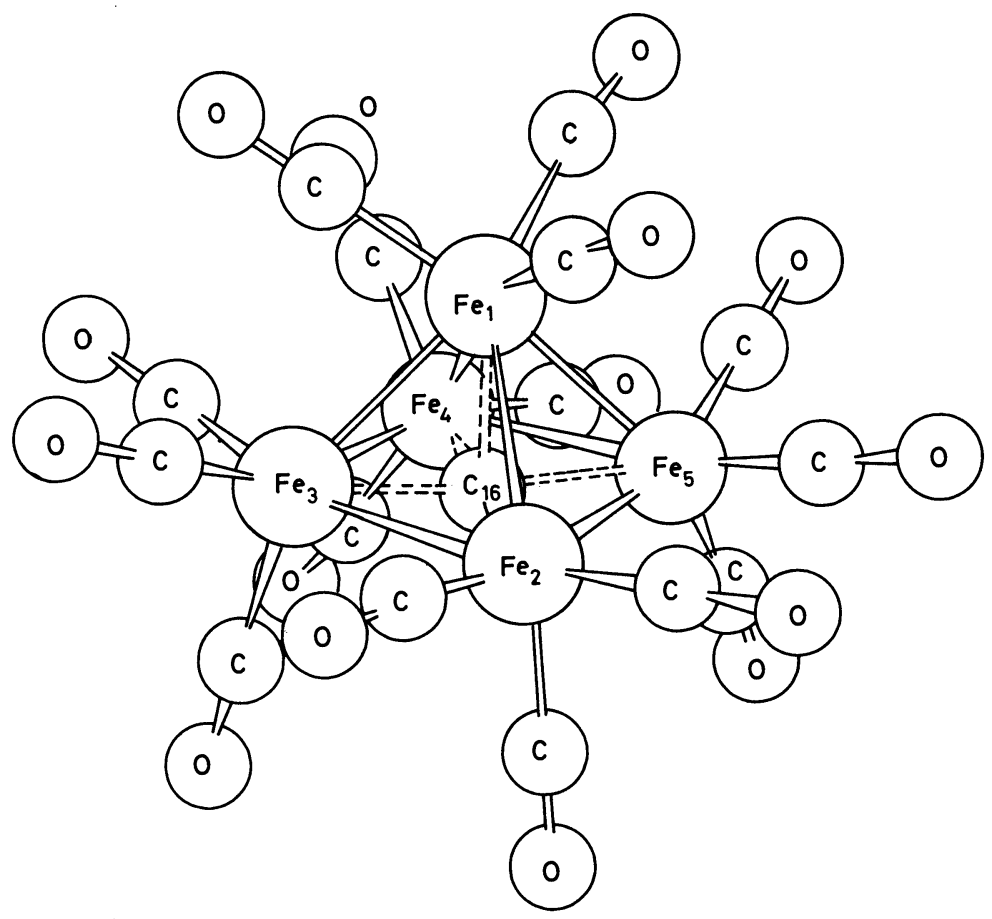

Figure 10

Another feature of these polynuclear aggregates is the ready formation of carbido-derivatives on controlled thermolysis of the carbonyls or the hydridocarbonyls, often in the presence of an organic solvent. The thermal decomposition of $\mathrm{Ru}_{3}(\mathrm{CO})_{12}$, in the higher boiling alkanes or as a solid, yields ${ }^{40}$ the carbido-carbonyl cluster $\mathrm{Ru}_{6} \mathrm{C}(\mathrm{CO})_{17}$; when the reaction is carried out in benzene or related solvents significant yields of the arene-substituted derivatives (arene) $\mathrm{Ru}_{6} \mathrm{C}(\mathrm{CO})_{14}$ occurs in which three of the terminal carbonyl groups are replaced by the arene group (Figure 9) ${ }^{40,41}$. The carbido clusters $\mathrm{M}_{5}(\mathrm{CO}){ }_{15} \mathrm{C}(\mathrm{M}=\mathrm{Os}, \mathrm{Ru})$ have also been prepared ${ }^{42}$ by alternative reactions and are similar to the iron derivative $\mathrm{Fe}_{5}(\mathrm{CO})_{15} \mathrm{C}$ obtained initially from the reaction of iron carbonyls with acetylene derivatives ${ }^{43}$. The structure of the iron adduct (Figure 10) contrasts the environment of the carbido group, which is in a facial position, with that of the hexanuclear ruthenium adduct when it is centred in the metal framework. The general chemistry of these carbido-derivatives is essentially unexplored; their ready formation, however, may suggest their potential intermediacy in any high temperature reaction process involving these carbonyls.

In contrast to the trinuclear species discussed above in which interaction with only two of the three metal centres was observed, the formation of compounds in which all three metal centres bond to the donor system may be readily achieved. As may be anticipated the substituted metal carbonyls are 
readily protonated in acid media ${ }^{44}$; with the ethylthiol derivative the protonated species provide a route to the preparation ${ }^{45}$ of the sulphur-bridged species $\mathrm{H}_{2} \mathrm{Ru}_{3}(\mathrm{CO})_{9} \mathrm{~S}$, in which the sulphur bridges to all three metal centres (Figure 11)

$$
\begin{aligned}
& \mathrm{H} \mathrm{Ru}(\mathrm{CO})_{10} \mathrm{SEt} \stackrel{\mathrm{H}^{+}}{\rightarrow}\left[\mathrm{H}_{2} \mathrm{Ru}_{3}(\mathrm{CO})_{10} \mathrm{SEt}\right]^{+} \\
& \stackrel{\mathrm{H}_{2} \mathrm{SO}_{4}}{\longrightarrow}\left[\mathrm{H}_{3} \mathrm{Ru}_{3}(\mathrm{CO})_{9} \mathrm{~S}\right]^{+} \stackrel{-\mathrm{H}^{+}}{\rightarrow}\left[\mathrm{H}_{2} \mathrm{Ru}_{3}(\mathrm{CO})_{9} \mathrm{~S}\right]
\end{aligned}
$$

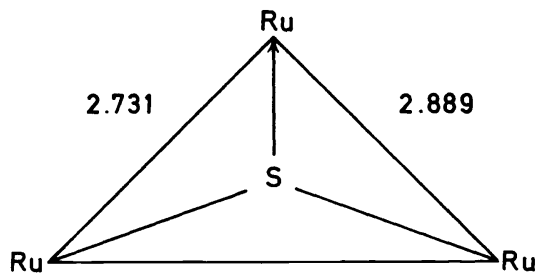

2.873
$R u-R u=2.85$

Figure 11

As may be expected from the facility with which hydrogen abstraction occurs with these metals, this compound and the related osmium compound may be prepared more directly from the reaction of the trinuclear carbonyls with hydrogen sulphide ${ }^{46}$. These derivatives and the related selenium and tellurium compounds ${ }^{47}$ are formally related to the paramagnetic cluster $\mathrm{Co}_{3}(\mathrm{CO})_{9} \mathrm{~S}$ and the diamagnetic compound $\mathrm{FeCo}_{2}(\mathrm{CO})_{9} \mathrm{~S}$ prepared by Dahl and coworkers ${ }^{48}$; in these compounds the sulphur atom is considered to donate four electrons to the bonding group framework, whilst bonding to the three metal centres. An alternative bonding pattern for sulphur has been determined in the compound $\left[\mathrm{Fe}_{3}(\mathrm{CO})_{9} \mathrm{~S}_{2}\right]$ which was obtained from the reaction of iron dodecacarbonyl with some sulphur donors ${ }^{49}$. The two sulphur atoms are considered to cap the two faces of the triangular grouping ${ }^{50}$. With a four electron donation from each sulphur, the dodecacarbonyl cluster unit has acquired two further electrons to the bonding scheme, and the structure has one edge of the metal triangle longer $(3.37 \AA)$ and does not involve a metalmetal bond. In contrast to this, the electronically related cobalt cluster $\mathrm{Co}_{3}\left(\mathrm{~h}^{5}-\mathrm{C}_{5} \mathrm{H}_{5}\right)_{3} \mathrm{~S}_{2}$ has been shown to have bicapped-sulphur bonding with essentially a $D_{3 \mathrm{~h}}$ geometry for the $\mathrm{Co}_{3} \mathrm{~S}_{2}$ fragment, and equal metal-metal bonds in a metal triangular unit ${ }^{51}$.

\section{(III) THE STRUCTURE AND REACTIVITY OF SIMPLE UNSATURATED ORGANIC GROUPS WITH POLYNUCLEAR CARBONYLS}

\section{(a) Olefins}

\section{(i) Mono-olefins}

The behaviour of simple olefins parallels the bonding patterns and cluster reactivity exemplified by inorganic donor systems. Thus, the reaction of tri-iron dodecacarbonyl with olefins leads to rupture of the metal cluster yielding mononuclear species in which the olefin donates two electrons to 


\section{J. LEWIS AND B. F. G. JOHNSON}

the metal orbitals. In contrast, both ruthenium and osmium dodecacarbonyls react with olefins to yield a variety of trinuclear products. With osmium, the reactions give high yields of complexes of the type (olefin) $\mathrm{Os}_{3}(\mathrm{CO})_{9}$, in which the olefin behaves electronically in a manner equivalent to $\mathrm{H}_{2} \mathrm{~S}$ with an overall donation of six electrons to the cluster unit. This involves the formation of two metal-hydrogen linkages, two carbon-metal bonds and the donation of two electrons from the carbon-carbon double bond-a bonding arrangement reminiscent of that suggested for olefin interaction with a metal surface (vide supra). Two classes of isomers have been obtained ${ }^{52}$ involving bonding of two metals to one carbon centre [Figure 12(a)] 1:1 bonding, or metal bonding to alternative carbons of the olefin bond [Figure 12(b)], 1:2 bonding. The $\mathrm{x}$-ray structure of the ethylene-osmium adduct has established a $1: 1$ bonding pattern for this compound ${ }^{53,54}$, whilst the structure of the cyclo-octene-ruthenium compound involves the $1: 2$ structure $^{52}$ (Figures 13 and 14).

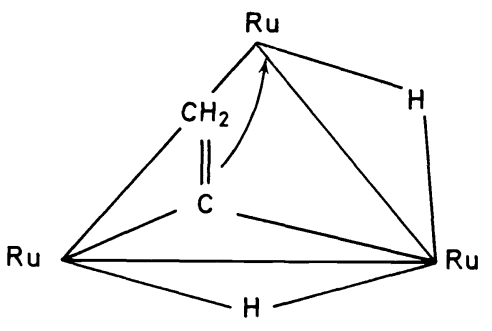

(a)

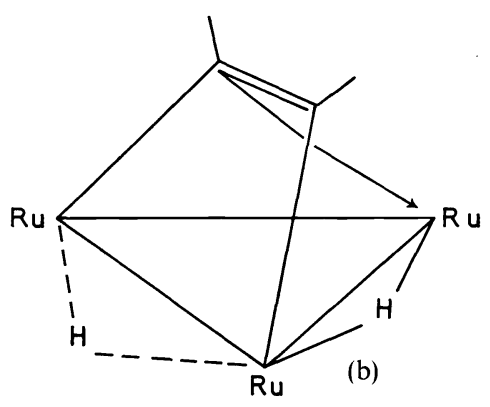

(b)

Figure 12

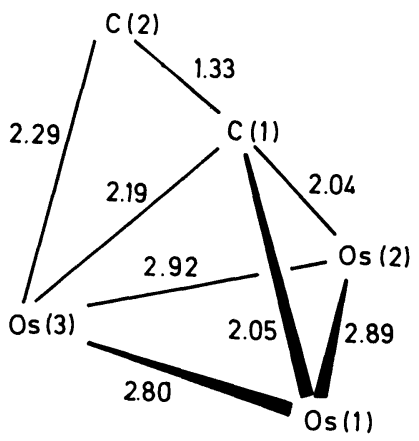

Figure 13

The ruthenium olefins of the 1:2 class (cyclo-octene), were formed in good yields from the parent dodecacarbonyl ${ }^{52}$, but the ethylene adduct was obtained ${ }^{55}$ from reaction with the hydride $\mathrm{H}_{4} \mathrm{Ru}_{4}(\mathrm{CO})_{12}$. The major product ${ }^{56}$ in this reaction was the ethylidyne compound, $\mathrm{H}_{3} \mathrm{Ru}_{3}(\mathrm{CO})_{9} . \mathrm{C}$. $\mathrm{CH}_{3}$. The structure of this compound is given in Figure $15^{57}$, and it is struc- 


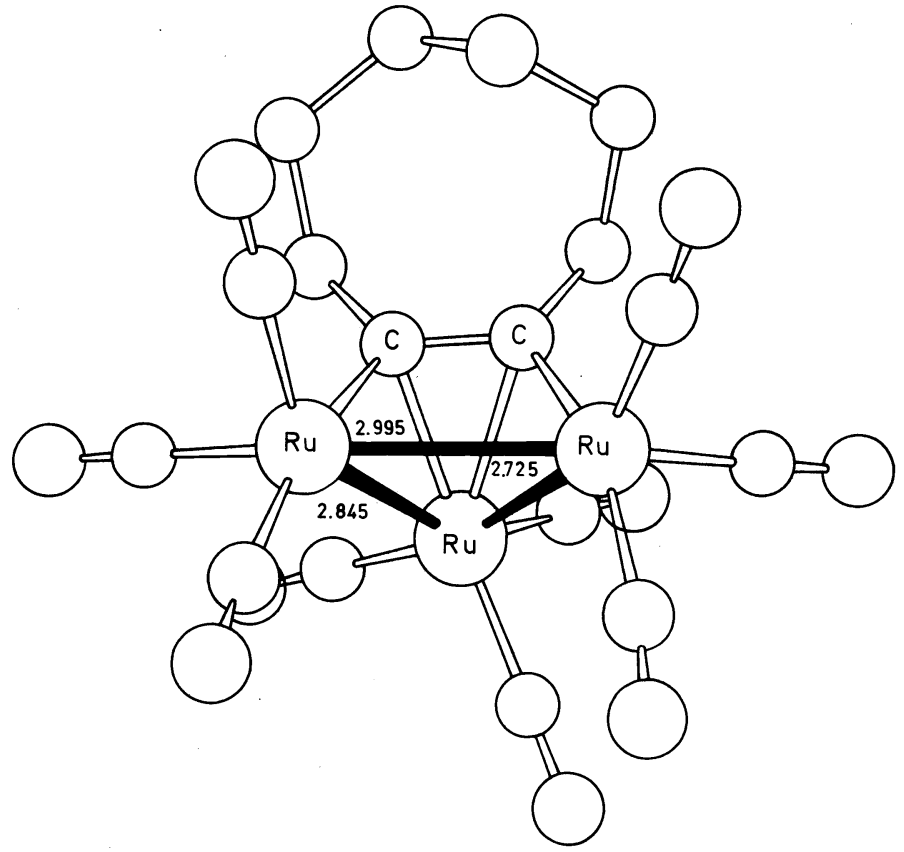

Figure 14

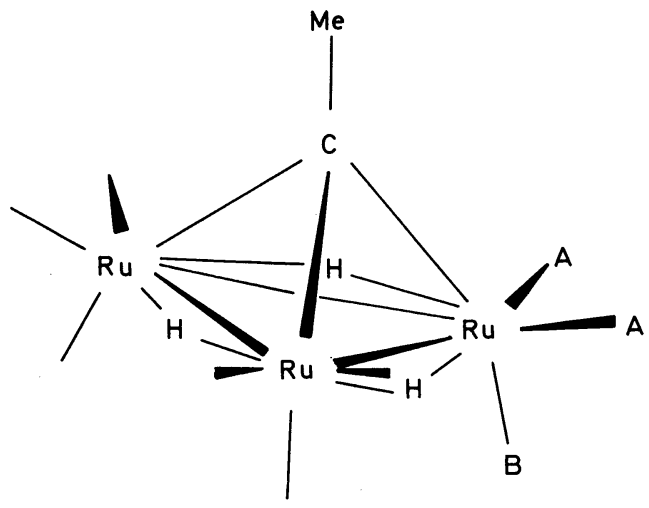

Figure 15

turally equivalent to the trinuclear cobalt complexes $\left[\mathrm{Co}_{3}(\mathrm{CO})_{9} \mathrm{C} \cdot \mathrm{CX}{ }_{3}\right]$, the chemistry of which has been extensively studied ${ }^{58}$. The ruthenium compound may also be obtained from the ethylene adduct by reaction with hydrogen ${ }^{56}$, and this is the method employed ${ }^{54,59}$ for the production of the related osmium compound $\left[\mathrm{H}_{3} \mathrm{Os}_{3}(\mathrm{CO})_{9} \mathrm{C} . \mathrm{CH}_{3}\right]$. In the olefin and ethylidene structures, all of the three metals are directly bonded to the organic group, but with the ethylene and cyclo-octene derivatives there is an asymmetrical 


\section{J. LEWIS AND B. F. G. JOHNSON}

bonding pattern. The structures of the olefin derivatives are considered to involve protonation of two of the edges of the metal triangles, corresponding to the larger intermetallic distances within the triangle. This would imply an asymmetric environment for both the metal-hydrogens and the hydrogens bonding to the carbon atoms. This difference has been detected in the n.m.r. spectra for both the ruthenium and osmium derivatives of ethylene $e^{54,55}$ and cyclo-octene for the metal-proton environment ${ }^{52}$, but the carbon-hydrogen asymmetry has only been detected with the ethylene adducts. This is, in part, associated with the much greater complexity of the signals in the n.m.r. spectra of the cyclo-octene derivative and, in part, with the greater distance of the centre from the metal framework.

Table 5. Coalescence temperatures for complexes (olefin) $\mathrm{M}_{3}(\mathrm{CO})_{9}$

\begin{tabular}{lccccc}
\hline \multirow{2}{*}{ Olefin } & \multirow{2}{*}{ Metal } & \multicolumn{2}{c}{ Metal-hydrogen } & \multicolumn{2}{c}{ Carbon-hydrogen } \\
\cline { 2 - 6 } & & $T^{\circ} \mathrm{C}$ & $\Delta G\left(\mathrm{kcal} \mathrm{mol}^{-1}\right)$ & $T^{\circ} \mathrm{C}$ & $\Delta G\left(\mathrm{kcal} \mathrm{mol}^{-1}\right)$ \\
\hline Cyclo-octene $^{52}$ & $\mathrm{Ru}$ & -9 & 11.8 & - & $-(\mathrm{a})$ \\
Cyclo-octene $^{52}$ & $\mathrm{Os}$ & 97 & 16.9 & - & $-(\mathrm{a})$ \\
${\text { Ethylene } 1: 1^{55}}$ & $\mathrm{Ru}$ & $>100$ & $>17.0$ & -4 & $13.4(\mathrm{a})$ \\
${\text { Ethylene } 1: 1^{54}}$ & $\mathrm{Os}$ & $>115$ & $>17.0$ & 72 & $20.3(\mathrm{~b})$ \\
Ethylene $1: 2^{55}$ & $\mathrm{Ru}$ & -5 & 12.0 & -20 & $12.1(\mathrm{~b})$ \\
\hline
\end{tabular}

(a) $\mathrm{d}^{8}$-toluene. (b) $\mathrm{CDCl}_{3}$.

These olefin complexes provide an interesting example of fluxional behaviour and Table 5 summarizes the data. The energy of coalescence of the two hydride signals associated with the metal-hydrogen bonding occur at much higher values than the energy of coalescence of the carbon protons, implying a different process for the equilibration of the two sites. The lower values for the energy of activation for ruthenium compounds are consistent with that discussed in other systems. In contrast to the $1: 1$ ethylenebonded system, the coalescence temperature of the metal-hydrogen signals and the energy of activation of the $1: 2$ species is much lower. By varying the pressure of ethylene in the reaction with the hydride, $\mathrm{H}_{4} \mathrm{Ru}_{4}(\mathrm{CO})_{12},(>20$ atoms), it has been possible ${ }^{55}$ to isolate the related ethylene complex in which the bonding of the olefin is of a similar type to that of cyclo-octene, namely, $1: 2$. The energy of exchange of the two classes of protons in this complex is the same, within experimental error and all these data imply a different mechanism for the exchange processes between the $1: 1$ and $1: 2$ complexes.

For the ethylene bonding in a 1:1 fashion a number of mechanisms for the exchange processes have been postulated. Basically, they involve either a migration of the hydrogen atoms around the metal triangle via a bridgeterminal process or breaking of the olefin-metal bond and a subsequent rotation about the olefin bond. In the ethylene-osmium system, it has been shown that for the complex $\mathrm{HDOs}_{3}(\mathrm{CO})_{9}\left(\mathrm{C}: \mathrm{CH}_{2}\right)$, the $\mathrm{C}-\mathrm{H}$ protons coalescence temperature in toluene is increased by $6^{\circ}$ without a significant rate of incorporation of deuterium into the organic group and the exchange 

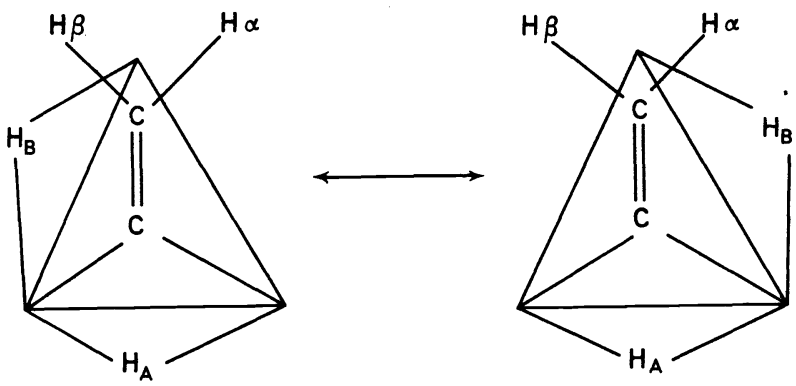

Figure 16

process is independent of concentration of the complex over the range studied. This implies that the mechanism of equilibration involves an intramolecular hydrogen migration within the metal framework ${ }^{60}$ which maintains the difference in environment of the two metal hydrogen protons $H_{A}$ and $H_{B}$, (Figure 16).

Further evidence in favour of this mechanism is provided by the use of the chiral centre, induced in an asymmetric olefin, on coordination to the metal cluster. The two isomers of the olefin complex, $\mathrm{H}_{2} \mathrm{Os}_{3}(\mathrm{CO})_{9} \mathrm{C}^{(1)}: \mathrm{C}^{(2)}\left(\mathrm{CH}_{3}\right)\left[\mathrm{CH}_{2} \mathrm{CH}\left(\mathrm{CH}_{3}\right)_{2}\right]$, were prepared and their n.m.r. spectra recorded in deuterochloroform ${ }^{60}$. The olefin carbon(2) is a chiral centre arising from coordination to the metal. On equilibration of the methyl resonances of the group directly bonded to this carbon(2)(i.e. isomerization), the diastereotopic splitting observed for the isopropyl methyl groups remains, implying that the equilibration process does not involve the breaking of the metal-olefin bond.

For the $1: 2$ bonded olefin adducts the similarity in the energies of the equilibration of the two different sets of protons suggests a common mechanism. This may occur either by a hydride-metal shift to produce a symmetrical intermediate, by producing a terminal hydride on each of the metals $\sigma$ bonded to the olefin or by a rotation of the olefin around the metal cluster as has also been suggested for the benzene adduct (vide infra).

Similar olefin derivatives have been isolated using a variety of other mono-olefins. In general, the $\alpha$-olefin derivatives bond in the $1: 1$ manner, and in certain instances, isomerization of internal olefins occurs to yield the $\alpha$-olefin which appears to be the preferentially bonding form. Thus ${ }^{55}$ both 1- and 2-cis-butene yield the same 1:1 isomer on reaction with the hydride $\mathrm{H}_{4} \mathrm{Ru}_{4}(\mathrm{CO})_{12}$, i.e. $\mathrm{H}_{2} \mathrm{Ru}_{3}(\mathrm{CO})_{9} \mathrm{C}: \mathrm{C}(\mathrm{H}) \mathrm{C}_{2} \mathrm{H}_{5}$.

The relationship between these ruthenium and osmium ethylidynes and the related cobalt complexes $\left[\mathrm{Co}_{3}(\mathrm{CO})_{9} \mathrm{C} . \mathrm{CH}_{3}\right]$ cited above, suggests an interesting comparison between the $1: 1$ ethylene derivative and the 'primary' carbonium ion species $\left[\mathrm{Co}_{3}(\mathrm{CO})_{9} \mathrm{C}: \mathrm{CH}_{2}^{+}\right]$recently reported by Seyferth ${ }^{61}$ for the related cobalt cluster. Protonation of the osmium-ethylene adduct, $\mathrm{H}_{2} \mathrm{Os}_{3}(\mathrm{CO})_{9} \mathrm{C}=\mathrm{CH}_{2}$, occurs in a variety of acid media to give ${ }^{62}$ the ion $\left[\mathrm{H}_{3} \mathrm{Os}_{3}(\mathrm{CO})_{9}\left(\mathrm{C}=\mathrm{CH}_{2}\right)\right]^{+}$. The same cation may be prepared also by hydride ion abstraction from the ethylidyne complex $\left[\mathrm{H}_{3} \mathrm{Os}_{3}(\mathrm{CO})_{9} \cdot \mathrm{C}_{2} \mathrm{CH}_{3}\right]$, 


\section{J. LEWIS AND B. F. G. JOHNSON}

with $\mathrm{Ph}_{3} \mathrm{C}^{+} \mathrm{BF}_{4}^{-}$in liquid sulphur dioxide. The cation is easily identified by n.m.r. spectroscopy and is formally related to the cobalt complex reported by Seyferth. However, below $-70^{\circ}$, two high-field signals are observed at 28.36 and $30.58 \tau$ with relative intensity of $1: 2$. This implies an asymmetric bonding of the 'olefin' to the metal cluster and the representation of this compound as a metal-protonated 1:1 bonded olefin [Figure 17 (left)] rather than as the symmetrical carbonium ion structure implied by Seyferth for the related cobalt complex, Figure 17 (right).
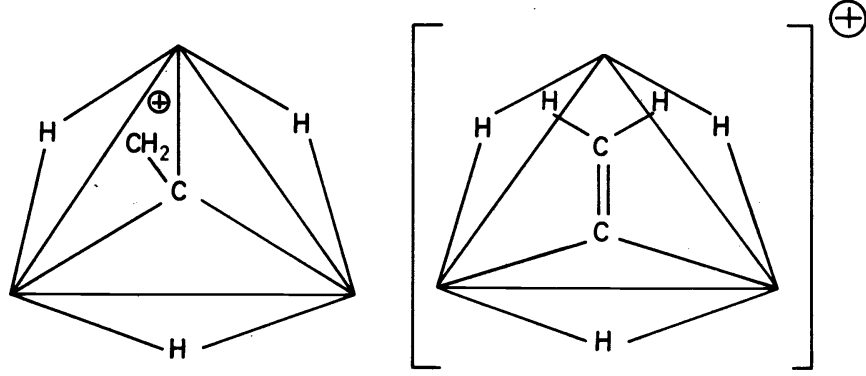

Figure 17

A novel bonding pattern for benzene has also been identified in these systems, although it was first recognized in more complex phosphine substitution products (vide infra). Benzene reacts slowly with $\mathrm{Os}_{3}(\mathrm{CO})_{12}$ in a sealed tube at $194^{\circ}$ to yield ${ }^{54}$, as one of the products, $\mathrm{H}_{2} \mathrm{Os}_{3}(\mathrm{CO})_{9}\left(\mathrm{C}_{6} \mathrm{H}_{4}\right)^{54}$. The n.m.r. spectrum indicated the bonding of the benzene as an orthophenylene group to two of the metals and the donation of the $\pi$-electron to the other metal, in a similar manner to that proposed for the phosphinesubstituted adducts (vide infra). There was only one high field signal observed and this was interpreted as indicating a rapid exchange process between the two hydride metal environments consistent with the mechanism of rotation of the benzene around the metal cluster as proposed for the phosphorus-substituted species.

Benzene compounds of this type were first prepared from the controlled thermolysis of the triphenylphosphine-substituted derivatives of triosmium duodecacarbonyl ${ }^{63}$. A complicated mixture was obtained, involving a variety of products in which not only had hydrogen abstraction occurred from the organic group with maintenance of the phosphorus-phenyl bond and formation of metal-carbon bonds, but also there took place the complete transfer of the 'benzene' grouping to the metal with the production of phosphido-bridging groups, Figure $18^{63}$. The latter compounds were considered to correspond to a coordinated 'benzyne' derivative, although as implied above they may equally well be formulated as 1:2 olefin derivatives similar to that obtained with cyclo-octene. An elegant study of the fluxional nature of complexes of the form $\left[\mathrm{Os}_{3}\left(\mathrm{C}_{6} \mathrm{H}_{4}\right)\left(\mathrm{EMe}_{2}\right)(\mathrm{CO})_{7}\right](\mathrm{E}=\mathrm{As}, \mathrm{P})$ has been carried out by Deeming and his co-workers ${ }^{64}$. In the structure of the related phenyl derivatives, Figure 18, the organic ring is bonded by orthocarbons to the metal triangle and the organic ring is inclined at about $70^{\circ}$ to 


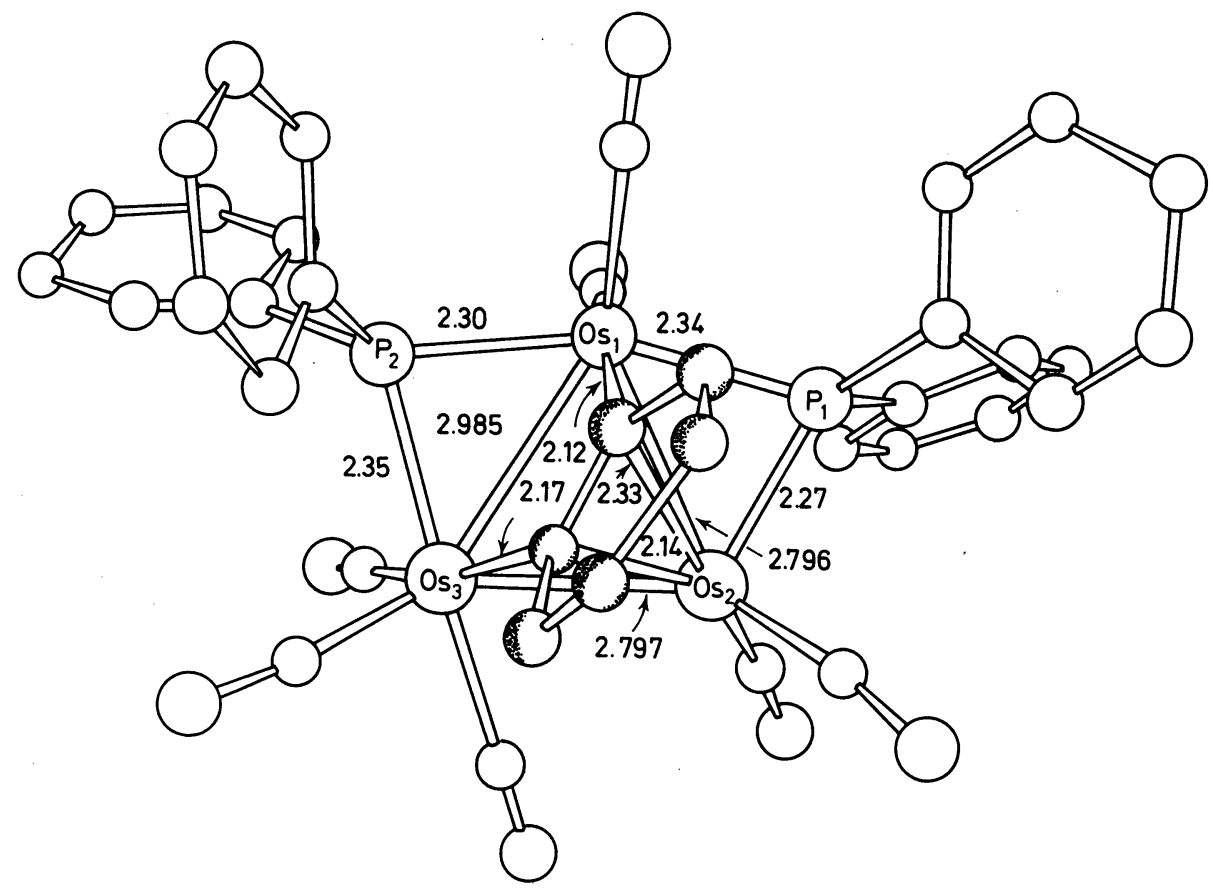

Figure 18

the metal ring system. Assuming a similar structure for the methyl derivatives, four different environments would be anticipated for the methyl and aryl hydrogens. The temperature variation of the n.m.r. spectra indicated that, at all temperatures studied, only two methyl signals were observed, whilst the protons on the aryl grouping showed a significant variation consistent with fluxional character. Two independent molecular motions were identified, as represented in Figure 19, corresponding to both a rotation and a 'flipping' of the organic group around the metal framework via the intermediacy of a carbonyl bridging group. The related ruthenium compounds have been prepared ${ }^{65}$ by the thermolysis of the corresponding trinuclear ruthenium carbonyl phosphine adduct. In the case of ruthenium a much greater preponderance of binuclear species was produced, consistent with the highest stability of the trinuclear osmium cluster unit.

In marked contrast to the behaviour of inorganic donor systems, relatively few organic systems have been isolated in which bonding occurs to only two of the three metal centres. One such series of compounds has recently been identified from the reaction of acetylene with the dihydride, $\mathrm{H}_{2} \mathrm{Os}_{3}$ $(\mathrm{CO})_{10}$. A facile reaction occurs to yield the vinylidene complex $\mathrm{HOs}_{3}$ $\left(\mathrm{CH}=\mathrm{CH}_{2}\right)(\mathrm{CO})_{10}$, in which a structure similar to that of the thiol-bridged complex $\mathrm{H} .(\mathrm{SEt}) \mathrm{Os}_{3}(\mathrm{CO})_{10}$ (Figure 8 ) is suggested ${ }^{66}$. The vinyl group bonding by a $\sigma$-bond to one metal donates an electron pair from the olefin to the other metal atom. This complex is smoothly hydrogenated to yield the $1: 1$ bonded ethylene complex $\mathrm{H}_{2} \mathrm{Os}_{3}(\mathrm{CO})_{9}\left(\mathrm{C}=\mathrm{CH}_{2}\right)$. 
J. LEWIS AND B. F. G. JOHNSON
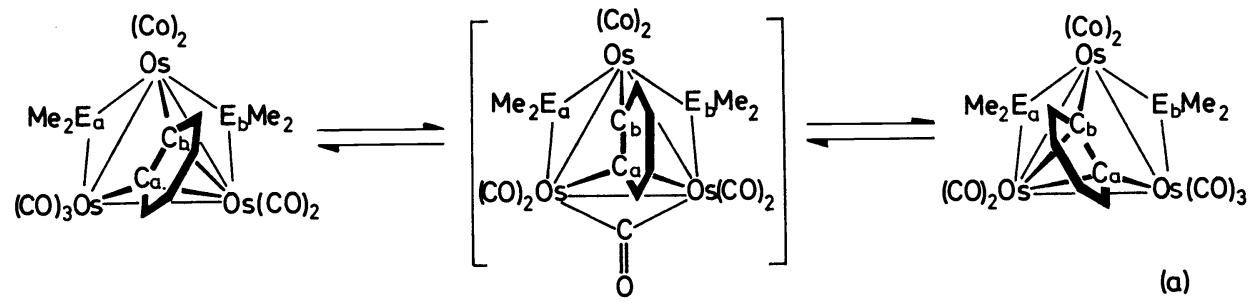

(a)
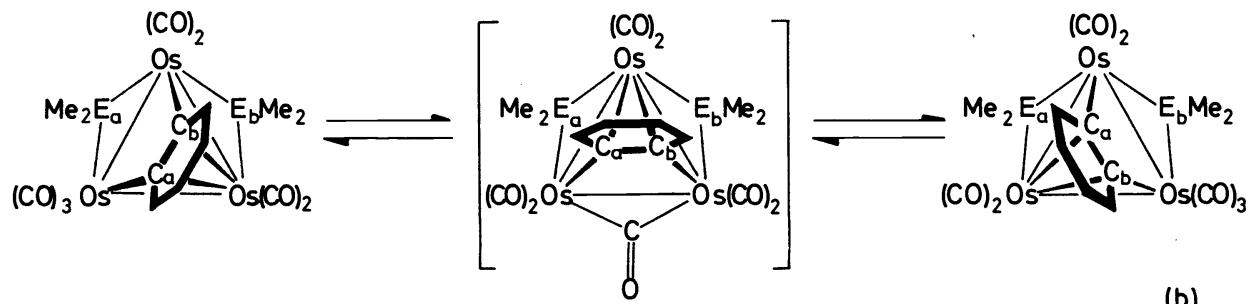

Figure 19

(b)

\section{(ii) Oligo-olefins}

The major studies with oligo-olefins have been restricted to ruthenium derivatives, using either the tetranuclear hydride carbonyl, $\mathrm{H}_{4} \mathrm{Ru}_{4}(\mathrm{CO})_{12}$ or the ruthenium dodecacarbonyl as the starting material. Reactions with non-conjugated dienes, such as $1: 5$ cyclo-octadiene lead ${ }^{52}$ to a variety of products with $\mathrm{H}_{4} \mathrm{Ru}_{4}(\mathrm{CO})_{12}$. Thus, a tetranuclear species involving a 'butterfly' bonding pattern, similar to that obtained by reactions of acetylenic derivatives with cobalt carbonyl, is readily obtained. The structure ${ }^{67}$ of the compound $\mathrm{Ru}_{4}(\mathrm{CO})_{11} \mathrm{C}_{8} \mathrm{H}_{10}$ is shown in Figure 20. Various trinuclear derivatives are also produced in this reaction; one of the major components is a monohydride $\mathrm{HRu}_{3}(\mathrm{CO})_{9} \mathrm{C}_{8} \mathrm{H}_{11}$, in which the organic group is bonded by a $\pi$-allyl grouping to the metal. This complex reacts smoothly with hydrogen to yield the cyclo-octene derivative described above, $\mathrm{H}_{2} \mathrm{Ru}_{3}(\mathrm{CO})_{9}$ $\left(\mathrm{C}_{8} \mathrm{H}_{12}\right)$; the cyclo-octene adduct is also produced ${ }^{52}$ by hydrogenation of the tetranuclear carbonyl cluster $\mathrm{Ru}_{4}(\mathrm{CO})_{10} \mathrm{C}_{8} \mathrm{H}_{10}$.

In contrast to the behaviour with the hydrido-carbonyl $\mathrm{H}_{4} \mathrm{Ru}_{4}(\mathrm{CO})_{12} 1: 5$ cyclo-octadiene reacts with $\mathrm{Ru}_{3}(\mathrm{CO})_{12}$ to yield, as the main product, the mononuclear compound (cyclo-octa-1,5-diene)-ruthenium tricarbonyl. This complex provides a useful starting point for the preparation ${ }^{68}$ of mononuclear diene systems by displacement reactions, as, in general, reactions with organic dienes lead to the formation of trinuclear clusters. The reaction of the conjugated 1:3 cyclo-octadiene with the ruthenium dodecacarbonyl yields a mixture of products which include the $\pi$-allyl derivative, $\mathrm{HRu}_{3}(\mathrm{CO})_{9}$ $\mathrm{C}_{8} \mathrm{H}_{11}$ obtained in the $1: 5$ octadiene- $\mathrm{H}_{4} \mathrm{Ru}_{4}(\mathrm{CO})_{12}$ systems and a dihydrido derivative $\mathrm{H}_{2} \mathrm{Ru}_{3}(\mathrm{CO})_{9} \mathrm{C}_{8} \mathrm{H}_{10}$ in which one of the double bonds is coordinated as a 1:2 olefin and one remains uncoordinated ${ }^{52}$.

In general, the conjugated diene systems readily react with either the hydrido-carbonyl, $\mathrm{H}_{4} \mathrm{Ru}_{4}(\mathrm{CO})_{12}$ or the parent carbonyl to yield $\pi$-allyl complexes. Thus butadiene yields the crotyl derivative, $\mathrm{HRu}_{3}(\mathrm{CO})_{9} \mathrm{C}_{4} \mathrm{H}_{5}$, in 
POLYNUCLEAR CARBONYLS OF GROUP VIII

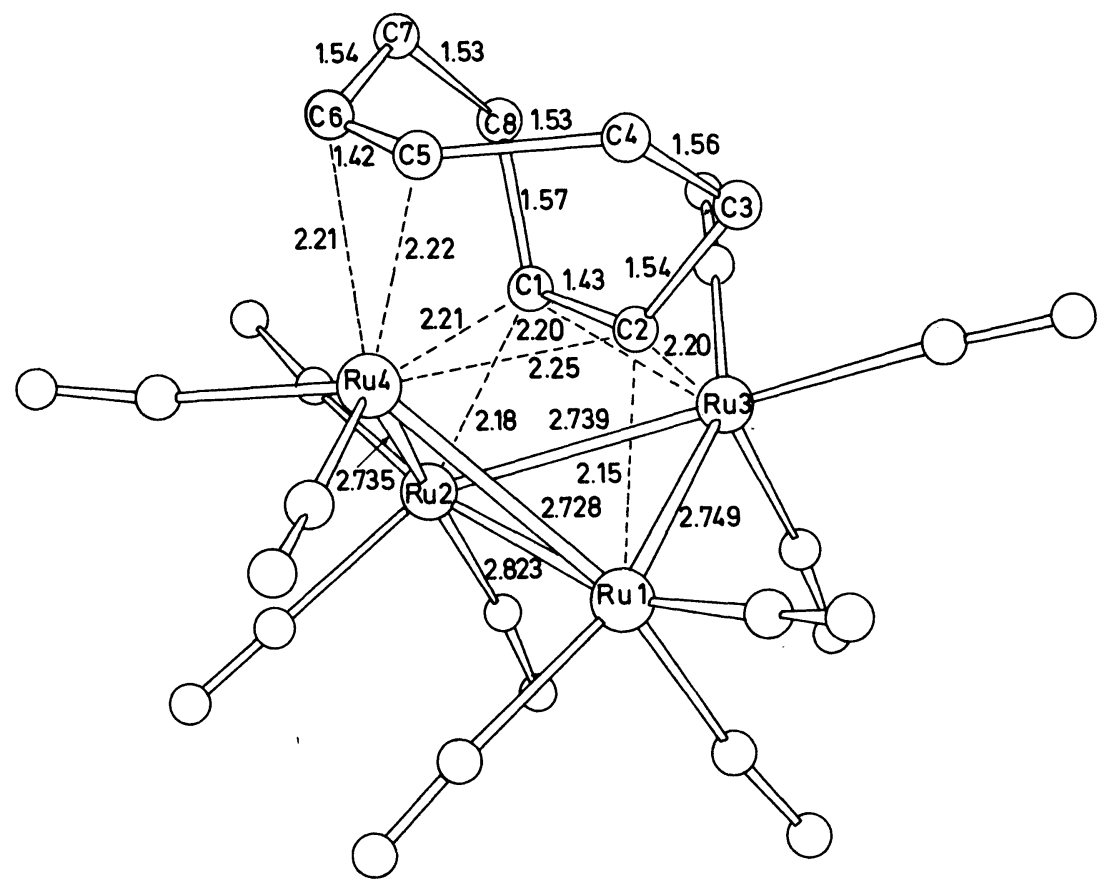

Figure 20

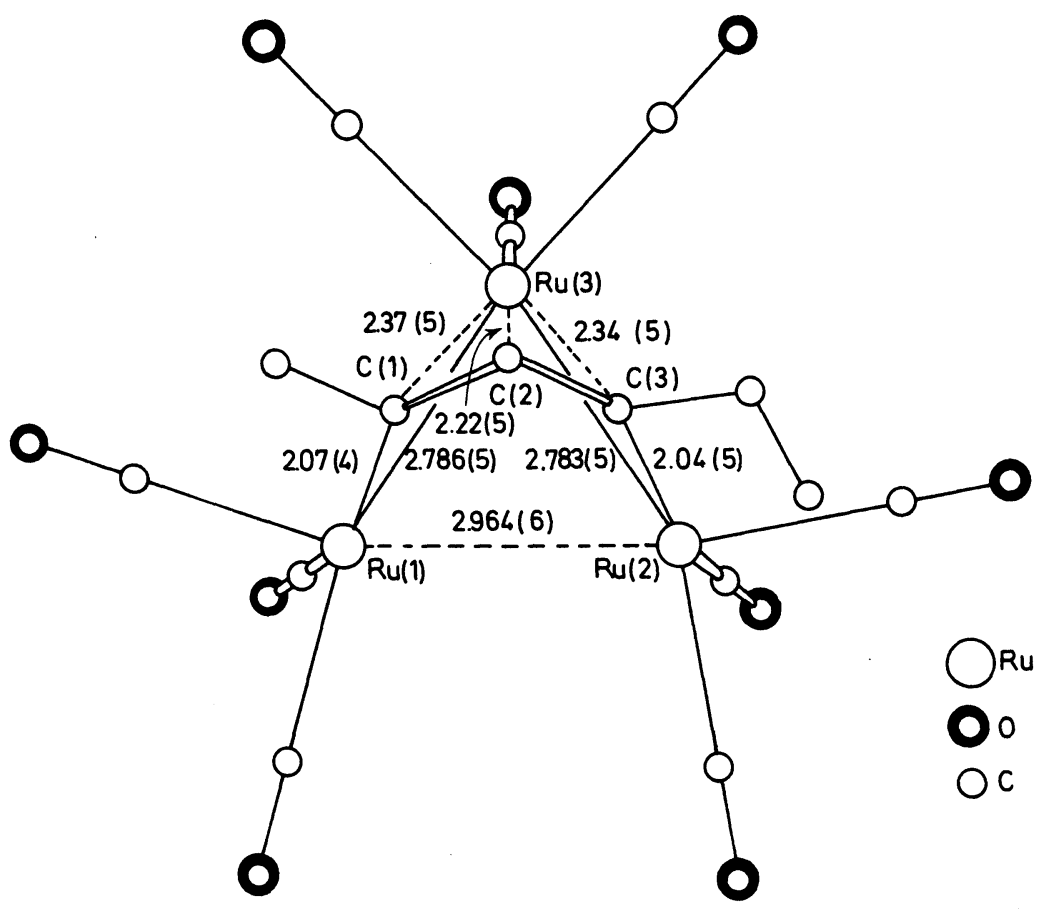

Figure 21 


\section{J. LEWIS AND B. F. G. JOHNSON}

which two metal-carbon $\sigma$-bonds are formed to the 1 and 3 carbon atoms of the $\pi$-allyl group and the $\pi$-electrons are donated to the remaining metal centre. The x-ray structure ${ }^{70}$ of the related adduct formed from cis-trans or trans-trans-hexa-2,4-diene is given in Figure 21. The metal hydride is considered to bond to the $R u(1)-R u(2)$ edge, consistent with the longer bond length. The ${ }^{13} \mathrm{C}$ n.m.r. spectra show that for the carbonyl groups, only one set of resonances, associated with the ruthenium atom $\mathrm{Ru}(3)$, is not affected by proton decoupling, also implying the bonding of the hydride to the $\mathrm{Ru}(1)-$ $\mathrm{Ru}(2)$ system.

The $\pi$-allyl derivatives may be formed also by hydrogen abstraction from mono-olefins. Thus 1-butene reacts with $\mathrm{Ru}_{3}(\mathrm{CO})_{12}$, to yield, amongst other products, the same crotyl derivative, $\mathrm{HRu}_{3}(\mathrm{CO})_{9} \mathrm{C}_{4} \mathrm{H}_{5}$, obtained ${ }^{55}$ from the reaction of butadiene with either $\mathrm{H}_{4} \mathrm{Ru}_{4}(\mathrm{CO})_{12}$ or $\mathrm{Ru}_{3}(\mathrm{CO})_{12}$. Hydrogenation of this compound gives the 2-butene coordinated cluster, $\mathrm{H}_{2} \mathrm{Ru}_{3}(\mathrm{CO})_{9}$ $\left(\mathrm{CH}_{3} \mathrm{C}=\mathrm{CCH}_{3}\right)^{55}$. The latter compound cannot be prepared directly from 2-butene, as this isomerizes to (presumably) the 1-butene in the presence of the ruthenium carbonyls, yielding a mixture of the crotyl derivatives and the $1: 1$ olefin adduct, $\mathrm{H}_{2} \mathrm{Ru}_{3}(\mathrm{CO})_{9}\left(\mathrm{C}=\mathrm{C}\left\langle\mathrm{C}_{2} \mathrm{H}_{5}\right)^{55}\right.$.

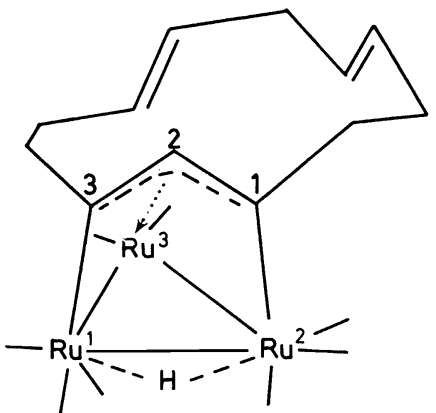

(a)

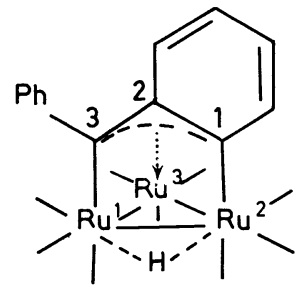

(b)

Selected parameters:

(a)

$$
\begin{aligned}
& R u^{1}-R u^{2} \\
& R u^{1}-R u^{3} \\
& R u^{2}-R u^{3} \\
& R u^{1}-C^{3} \\
& R u^{2}-C^{1} \\
& R u^{3}-C^{2}
\end{aligned}
$$

2.921

2.773

2.779

2.04

2.04

2.15

Figure 22 (b)

$2.914 \AA$

2.773

2.776

2.08

2.10

2.36

Studies with more complex polyene systems also involve the formation of $\pi$-allyl derivatives. Thus, the reaction of cyclododeca-1,5,9-triene with $\mathrm{Ru}_{3}(\mathrm{CO})_{12}$, gives as its main product ( $\sim 70$ per cent), the $\pi$-allyl bonded species whose structure has been determined ${ }^{71}$ by $\mathrm{x}$-radiography, Figure 22. This structure is closely related to that reported ${ }^{72}$ for the complex obtained by reaction of phenyl lithium with ruthenium duodecacarbonyl Figure 22(a). 
With cycloheptatriene, ruthenium dodecacarbonyl yields a trinuclear species involving two cycloheptatriene moieties, $\mathrm{Ru}_{3}(\mathrm{CO})_{6}\left(\mathrm{C}_{7} \mathrm{H}_{7}\right)\left(\mathrm{C}_{7} \mathrm{H}_{9}\right)$, the structure ${ }^{73}$ of which is represented diagrammatically in Figure 23. This molecule involves a dienyl group bonding to one ruthenium centre, with a delocalized bonding pattern between the $\mathrm{C}_{7} \mathrm{H}_{7}$ ring and two of the ruthenium atoms. Detailed n.m.r. studies over a temperature range have been able to establish the fluxional nature of both ring systems. The cycloheptadienyl group, $\mathrm{C}_{7} \mathrm{H}_{9}$, yields a temperature-variable spectrum, but the $\mathrm{C}_{7} \mathrm{H}_{7}$ ring is fluxional down to the lowest temperatures studied $\left(\sim-100^{\circ} \mathrm{C}\right)^{74}$.

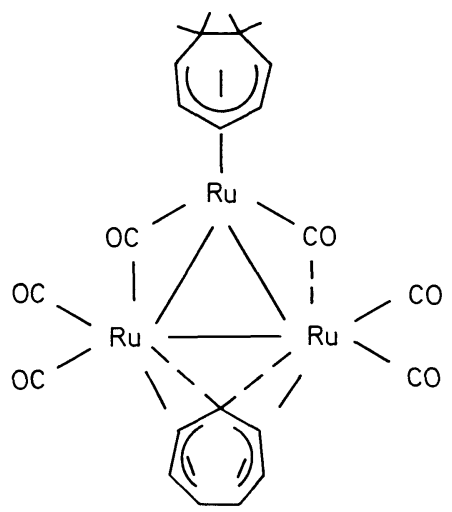

Figure 23

It is apparent from this description that the interaction of olefin groups with a series of metal centres provides a completely different series of bonding patterns to that obtained at a single metal centre. The various classes of bonding are summarized in Table 6. A study of these systems also emphasizes the dynamic nature of the groups coordinated to a metal cluster grouping. Comparable studies on acetylene systems produced evidence for the multibonding character of unsaturated organic groups to polynuclear aggregates but, in contrast to the behaviour with olefins, the pattern for osmium and ruthenium is much closer to the classical study of these systems with the iron trinuclear carbonyls, which was well documented from the work of Hübel and co-workers ${ }^{75}$.

For the ruthenium and osmium carbonyls, the stability of the trinuclear species is once again apparent. Reaction of methyl acetylene ${ }^{81}$ with the hydrido-osmium carbonyl, $\mathrm{H}_{2} \mathrm{Os}_{3}(\mathrm{CO})_{10}$, yields, amongst other products, approximately 40 per cent of three isomeric compounds $\mathrm{Os}_{3}(\mathrm{CO})_{10}\left(\mathrm{C}_{3} \mathrm{H}_{4}\right)_{2}$ which appear to be related to the dimeric iron complex isolated by Hübel ${ }^{75}$, and shown in Figure 24. The complexes contain the metal 'quinone' structure and are formulated on the basis of n.m.r. and infra-red spectroscopy as isomers of the type depicted in Figure 25.

One mechanism for the ready polymerization of acetylenes, induced by iron dodecacarbonyl, has been elegantly illustrated from the structural 


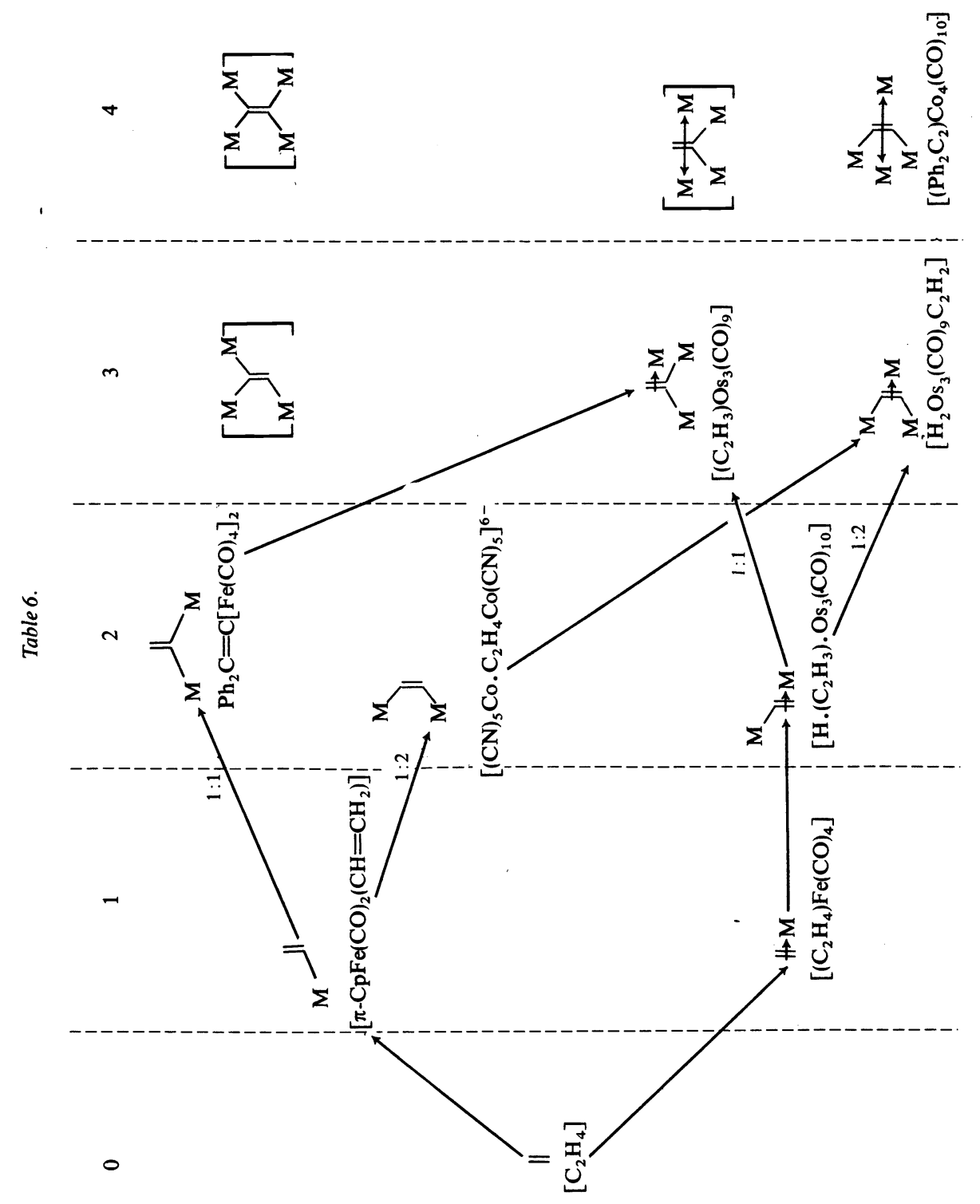

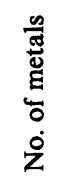




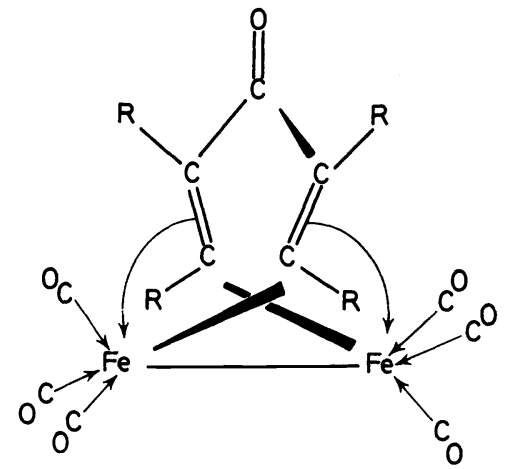

Figure 24

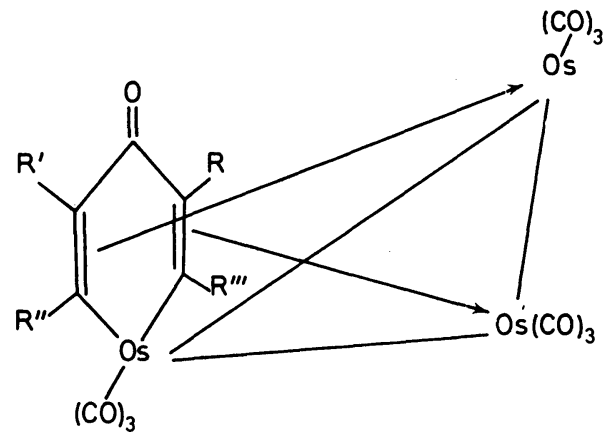

$$
\begin{aligned}
& R^{\prime}=R=M e \\
& R^{\prime}=R^{\prime \prime \prime}=M e \\
& R^{\prime \prime}=R^{\prime \prime \prime}=M e
\end{aligned}
$$

Figure 25

studies of intermediates. Figure 26 shows the structures of the various complexes involved in the dimerization of diphenylacetylene ${ }^{75}$. An important difference between acetylene and olefin reactions is the ease with which two acetylene groups are added to the trinuclear cluster: no trinuclear olefin aggregates are known, corresponding to the 'violet' isomer. This may reflect the 'saturation' of the metal bonding system for hydrogen on interaction with one mole of an olefin. However, the close relationship between $1: 2$ bonded olefin complexes and acetylene adducts has been shown ${ }^{78}$ from the reactions of ruthenium carbonyl with diphenylacetylene in alkaline aqueous methanol (Figure 27). This produces the dihydrido-carbonyl complex $\mathrm{H}_{2} \mathrm{Ru}_{3}(\mathrm{CO})_{9}$ $\mathrm{C}_{2} \mathrm{Ph}_{2}$, in which the organic group is bonded as a $1: 2$ olefin. Reaction of this complex in petroleum ether with excess of diphenylacetylene yields a complex, $\mathrm{Ru}_{3}(\mathrm{CO})_{8}\left(\mathrm{C}_{2} \mathrm{Ph}_{2}\right)_{2}$, which is the ruthenium analogue of the violet iron 

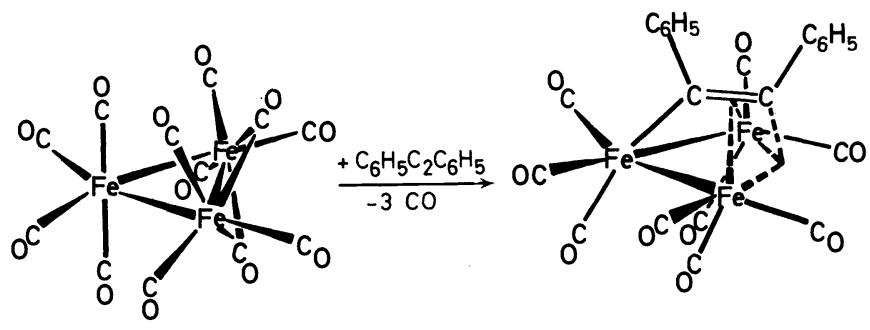

(a) $\mathrm{Fe}_{3}(\mathrm{CO})_{12}$

(b) $\mathrm{C}_{6} \mathrm{H}_{5} \mathrm{C}_{2} \mathrm{C}_{6} \mathrm{H}_{5} \mathrm{Fe}_{3}(\mathrm{CO})_{8}$

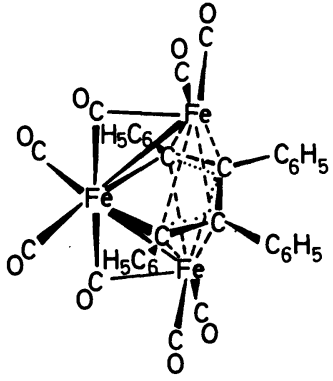

Isomerization $+\mathrm{C}_{6} \mathrm{H}_{5} \mathrm{C}_{2} \mathrm{C}_{6} \mathrm{H}_{5} \downarrow-\mathrm{CO}$

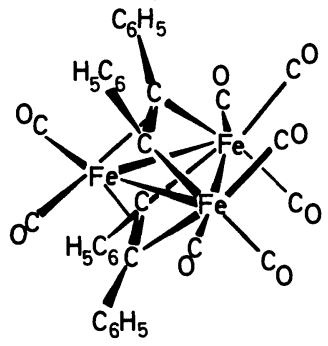

Figure 26

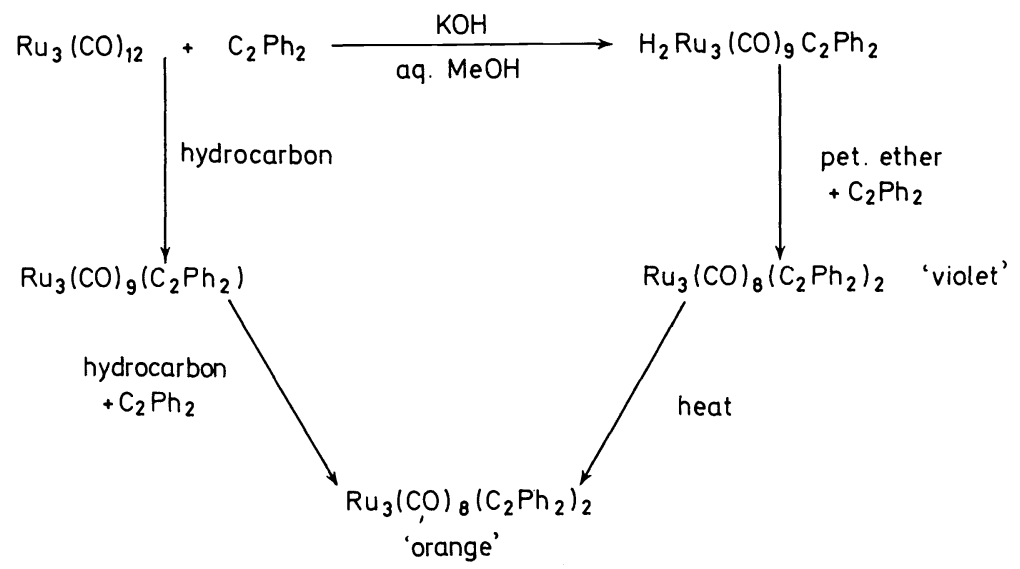

Figure 27

isomer, diphenylacetylene presumably acting as a hydrogen acceptor in this reaction.

This work emphasizes the close analogy between the bonding patterns of olefins and acetylenes on these aggregates, with the complete equivalence in structural forms of the olefin to the acetylene, on loss of the hydrogen to the metal network. The analogous behaviour of acetylene and olefin on metal surfaces may be related to this type of situation. 
If, indeed, the limitation for multiple interaction with olefins is the hydrogen acceptor power of the unit, it is of obvious interest to extend studies to higher polynuclear systems where more than one 'triangular cluster' is available and more than one olefin may be accommodated. It is significant that reactions of olefins with higher polynuclear aggregates, e.g. $\mathrm{Os}_{6}(\mathrm{CO})_{18}$, leads initially to products, presumably of a similar nature to those obtained in the trinuclear systems, but results on more protracted interaction in the formation of polymerization products of the olefin, still bonded to the metal carbonyl aggregates ${ }^{8}$ and involving molecular units of $\mathrm{C}_{4}, \mathrm{C}_{6}$ and $\mathrm{C}_{8}$ fragments.

It is of general importance to recognize that much of the chemistry in these polynuclear aggregates differs very significantly from that of the simple metal systems; the bonding patterns exhibited, if not providing an exact equivalence with the behaviour of organic species on metal surfaces, illustrates a new range of interactions which differs from that observed for mononuclear complexes. These reactions emphasize in particular the facility with which metal-carbon and metal-hydrogen bonds may be formed from organic molecules, on interaction with multimetal centres.

\section{REFERENCES}

1 T. A. Clarke, I. D. Day and R. Mason, Chem. Commun. 331 (1974);

T. A. Clarke, R. Mason and M. Tescari, Proc. Roy. Soc. A, 331, 321 (1972).

2 N. Primet and N. Sheppard, J. Catalysis, in press (1974).

3 An excellent review of both the structure and chemistry of polynuclear species is given by R. B. King, Progr. Inorg. Chem., Vol. 15, p. 287. Edited by S. J. Lippard. Wiley: New York (1972).

4 C. R. Eady, B. F. G. Johnson and J. Lewis, J. Organometal. Chem. 37, C39 (1972).

5 E. R. Corey, L. F. Dahl and W. Beck, J. Amer. Chem. Soc. 85, 1202 (1963);

S. F. A. Kettle, J. Chem. Soc. (A), 314 (1967).

6 K. Wade, Electron Deficient Compounds. Nelson: London (1971).

7 R. Mason, K. M. Thomas and D. M. P. Mingos, J. Amer. Chem. Soc. 95, 3802 (1973):

8 C. R. Eady, B. F. G. Johnson and J. Lewis-unpublished results.

9 M. A. Neumann, T. Toan and L. F. Dahl, J. Amer. Chem. Soc. 94, 3383 (1972);

T. Toan, W. P. Fehlhammer and L. F. Dahl, J. Amer. Chem. Soc. 94, 3389 (1972);

G. L. Simon and L. F. Dahl, J. Amer. Chem. Soc. 95, 2164 (1973);

See also J. A. Ferguson and T. J. Meyer, J. Amer. Chem. Soc., 94, 3409 (1972).

10 P. D. Frisch and L. F. Dahl. J. Amer. Chem. Soc. 94, 5082 (1972).

11 B. K. Teo, M. B. Hall, R. F. Fenske and L. F. Dahl, J. Organometal. Chem. 70, 413 (1974).

12 R. Mason and D. M. P. Mingos, J. Organometal. Chem. 50, 53 (1973).

13 D. M. P. Mingos. J. Chem. Soc. A, 133 (1974).

14 See R. D. Adams and F. A. Cotton, Inorg. Chem. 13, 249 (1974).

15 See D. J. Thornhill and A. R. Manning, J. Chem. Soc. Dalton, 2086 (1973).

16 O. A. Gansow, A. R. Burke and G. N. La Mar, Chem. Commun. 456 (1972).

17 J. Evans, B. F. G. Johnson, J. Lewis and T. W. Matheson, J. Amer. Chem. Soc. 97, 1245 (1975).

18 J. Evans, B. F. G. Johnson, J. Lewis, J. R. Norton and F. A. Cotton, Chem. Commun. 807 (1973).

19 B. F. G. Johnson, J. Lewis and T. W. Matheson, Chem. Commun. 441 (1974).

${ }^{20}$ F. A. Cotton, L. Kruczynski, B. L. Shapiro and L. F. Johnson, J. Amer. Chem. Soc. 94, 6191 (1972).

21 S. Martinengo, P. Chini, V. G. Albano, F. Cariati and T. Salvatori, J. Organometal. Chem. 59, 379 (1973).

22 L. F. Dahl and D. L. Smith, J. Amer. Chem. Soc. 84, 2450 (1962).

23 J. R. Norton, J. P. Collman, G. Dolcetti and W. T. Robinson, Inorg. Chem. 11, 382 (1972).

${ }^{24}$ L. F. Dahl and J. F. Blount, Inorg. Chem. 4, 1373 (1965). 


\section{J. LEWIS AND B. F. G. JOHNSON}

25 P. Chini, S. Martinengo, D. J. A. McCaffrey and B. T. Heaton, Chem Commun. 310 (1974).

26 J. A. Connor, H. A. Skinner and Y. Virmani, Symp. Faraday Soc. (1974), 8, in press.

27 B. F. G. Johnson, J. Lewis and P. A. Kilty, J. Chem. Soc. A, 2859 (1968).

28 C. W. Bradford and R. S. Nyholm, Chem. Commun. 867 (1968).

29 M. I. Bruce and F. G. A. Stone, Chem. Commun. 684 (1966).

30 G. Raper and W. S. McDonald, J. Chem. Soc. A, 3430 (1971).

31 J. P. Candlin and A. C. Shortland, J. Organometal. Chem. 16, 289 (1969);

F. Piacenti, M. Bianchi, E. Benedetti and G. Braca, Inorg. Chem. 7, 1815 (1968).

32 A. J. Deeming, B. F. G. Johnson and J. Lewis, J. Organometal. Chem. 17, P40 (1969);

A. J. Deeming, B. F. G. Johnson and J. Lewis, J. Chem. Soc. A, 897 (1970).

33 G. R. Crooks, B. F. G. Johnson, J. Lewis and I. G. Williams, J. Chem. Soc. A, 797 (1969).

34 R. Greatrex, N. N. Greenwood, I. Rhee, M. Ryang and S. Tsutsumi, Chem. Commun. 1193 (1970).

35 H. D. Kaesz, S. A. R. Knox, J. W. Koepke and R. B. Saillant, Chem. Commun 477 (1971).

36 J. Norton, D. Valentine Jr and J. P. Collman, J. Amer. Chem. Soc. 91, 7537 (1969).

37 R. Mason and A. I. B. Rae, J. Chem. Soc. A, 778 (1968).

38 C. R. Eady, B. F. G. Johnson and J. Lewis, J. Organometal. Chem. 37, C39 (1972).

39 C. R. Eady, B. F. G. Johnson and J. Lewis-unpublished results.

40 B. F. G. Johnson, J. Lewis and I. G. Williams, J. Chem. Soc. A, 901 (1970);

A. Sirigu, M. Bianchi and E. Benedetti, Chem. Commun. 596 (1969).

41 R. Mason and W. R. Robinson, Chem. Commun. 468 (1968).

42 C. R. Eady, B. F. G. Johnson, J. Lewis and T. W. Matheson, J. Organometal. Chem. 57, C82 (1973).

43 E. H. Braye, L. F. Dahl, W. Hübel and D. L. Wampler, J. Amer. Chem. Soc. 84, 4633 (1962).

44 A. J. Deeming, B. F. G. Johnson and J. Lewis, J. Chem. Soc. A, 2517 and 2967 (1970).

45 A. J. Deeming, R. Ettorre, B. F. G. Johnson and J. Lewis, J. Chem. Soc. A, 1797 (1971).

46 A. J. Deeming and M. Underhill, J. Organometal. Chem. 42, C60 (1972).

47 O. Gambino, E. Sappa and G. Cetini, J. Organometal. Chem. 35, 375 (1972).

48 C. H. Wei and L. F. Dahl, Inorg. Chem. 6, 1229 (1967);

S. A. Khattab, L. Markó, G. Bor and B. Markó, J. Organometal. Chem. 1, 373 (1964).

49 R. Havlin and G. R. Knox, J. Organometal. Chem. 4, 247 (1965);

R. B. King, Inorg. Chem. 2, 326 (1963).

50 C. H. Wei and L. F. Dahl, Inorg. Chem. 4, 493 (1965).

51 P. D. Frisch and L. F. Dahl, J. Amer. Chem. Soc. 94, 5082 (1972).

52 A. J. Canty, A. J. P. Domingos, B. F. G. Johnson and J. Lewis, J. Chem. Soc. A, 2056 (1973); G. J. Gainsford, R. Mason and K. M. Thomas-unpublished results.

53 A. J. Deeming and M. Underhill, Chem. Commun. 277 (1973).

54 A. J. Deeming, S. Hasso and M. Underhill, J. Chem. Soc. (Dalton), 1614 (1975).

55 A. J. Canty, B. F. G. Johnson and J. Lewis-unpublished results.

56 A. J. Canty, B. F. G. Johnson, J. Lewis and J. R. Norton, Chem. Commun. 1331 (1972).

57 G. M. Sheldrick and J. P. Yesinowski, J. Chem. Soc. (Dalton), 873 (1975).

58 B. R. Penfold and B. H. Robinson, Accounts Chem. Res. 6, 73 (1973).

59 J. P. Yesinowsky and D. Bailey. J. Organometal. Chem. 65, C27 (1974).

60 W. G. Jackson, B. F. G. Johnson and J. Lewis, J. Organometal. Chem. (1975), in press.

61 D. Seyferth, G. H. Williams and D. D. Traficante, J. Amer. Chem. Soc. 96, 604 (1974).

62 A. J. Deeming, S. Husso, M. Underhill, A. J. Canty, B. F. G. Johnson, W. G. Jackson, J. Lewis and T. W. Matheson, Chem. Commun. 807 (1974).

63 G. J. Gainsford, J. M. Guss, P. R. Ireland, R. Mason, C. W. Bradford and R. S. Nyholm, J. Organometal. Chem. 40, C70 (1972);

C. W. Bradford, R. S. Nyholm, G. J. Gainsford, J. M. Guss, P. R. Ireland and R. Mason, Chem. Commun. 87 (1972).

64 A. J. Deeming, R. E. Kimber and M. Underhill, J. Chem. Soc. Dalton, 2589 (1973).

65 M. I. Bruce, G. Shaw and F. G. A. Stone, J. Chem. Soc. Dalton, 1667 (1973).

66 A. J. Deeming, S. Hasso and M. Underhill-unpublished results.

67 R. Mason and K. M. Thomas, J. Organometal. Chem. 43, C39 (1972).

68 A. J. P. Domingos, B. F. G. Johnson and J. Lewis, J. Organometal. Chem. 49, C33 (1973).

69 O. Gambino, M. Valle, S. Aime and G. A. Vaglio, Inorg. Chim. Acta, 8, 71 (1974);

See also T. M. Whitesides and R. A. Budnik, Chem. Commun. 87 (1973). 
${ }^{70}$ M. Evans, M. Hursthouse, E. W. Randall, E. Rosenberg, L. Milone and M. Valle, Chem. Commun. 545 (1972).

71 M. I. Bruce, M. A. Cairns and M. Green, J. Chem. Soc. Daltom, 1293 (1972);

M. I. Bruce, M. A. Cairns, A. Cox, M. Green, M. D. H. Smith and D. Woodward, Chem. Commun. 735 (1970).

72 A. W. Parkins, E. O. Fischer, G. Huttner and D. Regler, Angew. Chem. Internat. Ed. 9, 633 (1970).

73 R. Bau, J. C. Burt, S. A. R. Knox, R. M. Laine, R. P. Phillips and F. G. A. Stone, Chem. Commun. 726 (1973).

74 T. H. Whitesides and R. A. Budnik, Chem. Commun. 302 (1974).

75 An excellent review of this field to 1968 is W. Hübel, Organic Syntheses via Metal Carbonyls, edited by I. Wender and P. Pino, Vol. I, p 273. Interscience: New York (1968).

76 E. Koerner von Gustorf and R. Wagner, Angew. Chem. Internat. Ed. 10, 910 (1971).

77 E. W. Abel, T. Blackmore and R. J. Whitlet, Inorg. Chem. Nucl. Letters (1974).

78 O. Cambino, E. Sappa and G. Cetini, J. Organometal. Chem. 44, 185 (1972).

79 F. A. Cotton-private communication (1974).

80 J. Evans, B. F. G. Johnson, J. Lewis, T. W. Matheson and J. R. Norton, to be published.

81 W. G. Jackson, B. F. G. Johnson, J. Lewis and J. Kelland, J. Organometal. Chem., in press. 